\title{
A shake table investigation of dynamic behavior of pile supported bridges in liquefiable soil deposits
}

\author{
Piyush Mohanty ${ }^{1}$, Xu Dan², Suryakant Biswal ${ }^{3}$, Subhamoy Bhattacharya ${ }^{4}$
}

Piyush Mohanty: University of Surrey \& Scientist, CSIR- Central Building Research Institute, India. Geotechnical Engineer, Email: pyushmohanty@gmail.com

$\mathrm{Xu}$ Dan: PhD Student, Institute of Engineering Mechanics, China. Email: xudan iem@yeah.net

Suryakant Biswal: Post-doctoral Researcher, University of Surrey, UK. Email: surya.civil.iisc@gmail.com

Subhamoy Bhattacharya: Chair, Geomechanics Group, University of Surrey, UK.Email: s.bhattacharya@surrey.ac.uk

\begin{abstract}
:
Bridges are a part of vital infrastructure, which should operate even after the disaster to keep the emergency services running. There have been numerous bridge failures due to the liquefaction during major past earthquakes. Among other categories of failures, mid span collapse (without the failure of abutments) of pile supported bridges, founded in liquefiable deposits are still observed even in most recent earthquakes. This mechanism of collapse is attributed to the effects related to the differential elongation of natural period of the individual piers, during liquefaction. A shake table investigation has been carried out in this study to verify mechanisms behind midspan collapse of pile supported bridges in liquefiable deposits. A typical pile supported bridge is scaled down and its foundations pass through the liquefiable loose sandy soil and rest in dense gravel layer. White noise motions of increasing acceleration magnitude have been applied to initiate progressive liquefaction and to characterize the dynamic features of the bridge. It has been found that as the liquefaction sets in the soil, the natural frequency of individual bridge support reduces with the highest reduction occurring near the central spans. As a result, there is differential lateral displacement and bending moment demand on the piles. It has also been observed that for the central pile, the maximum bending moment in the pile will occur at a higher elevation, as compared to that of the interface of soils of varied stiffness, unlike the abutment piles. The practical implications of this research are also highlighted.
\end{abstract}

Keywords:

Bridges, midspan failure, liquefaction, bridge collapse, earthquake, pile, shake table test, natural frequency, 
1. Introduction

\subsection{Motivation}

Bridges are a part of vital infrastructure, which should operate even after the disaster to keep the emergency services running. However, collapse of pile supported bridges due to liquefaction related effects are still observed even after recent major earthquakes. The collapse of Palu bridge due to Indonesia earthquake (2018), Rokko bridge collapse due to Tohoku earthquake (Japan) (2011), Miaoziping bridge collapse due to Wenchuan earthquake (China) (2008), Gaoyuan bridge collapse in case of Wenchuan earthquake (2008) (see Fig.1) are few amongst many examples.
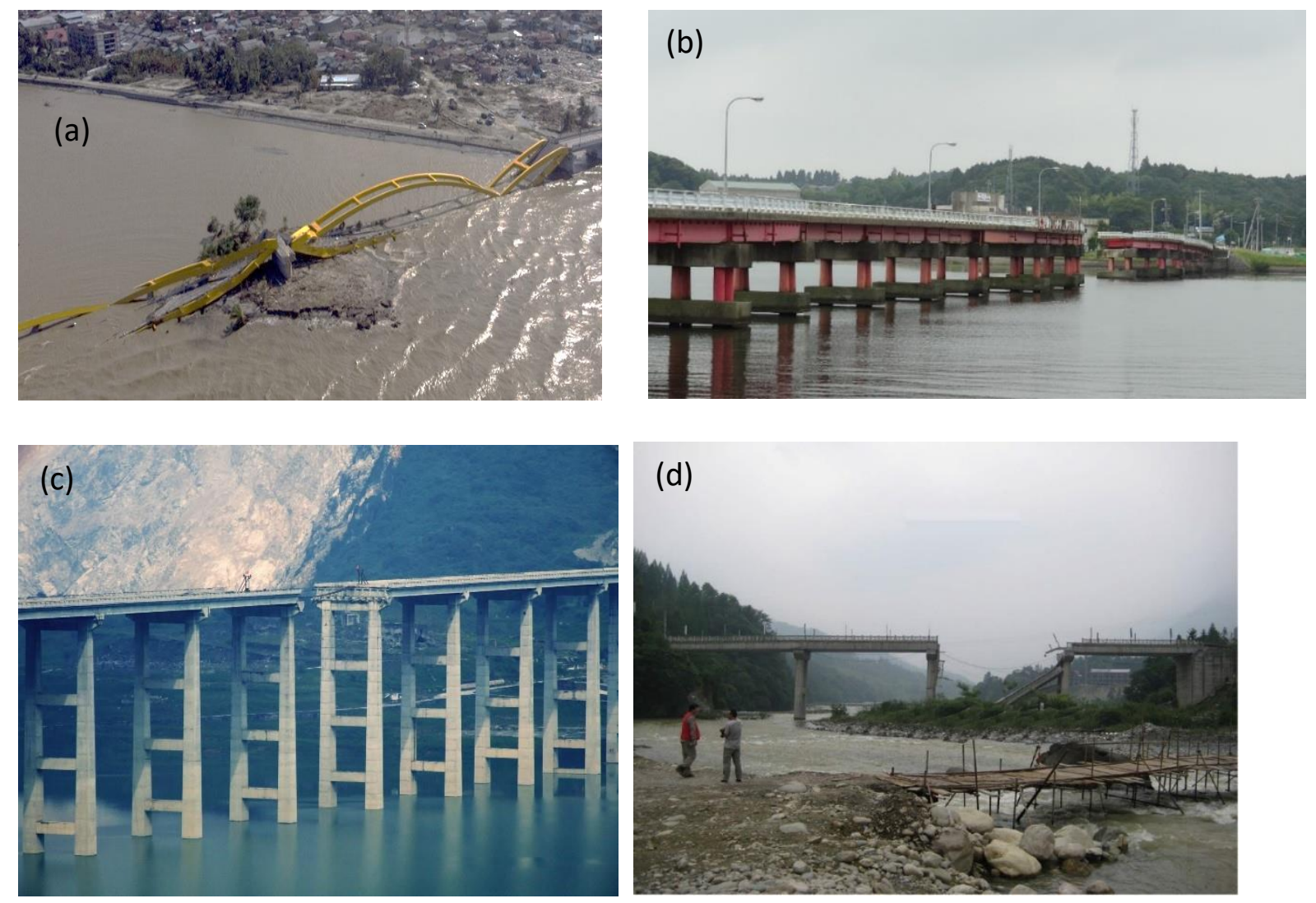

Fig. 1 Collapse of bridges due to liquefaction in soil. (a) Palu bridge due to Indonesia earthquake (2018), (b) Rokko bridge due to Tohoku earthquake (2011), (c) Miaoziping bridge due to Wenchuan earthquake (2008), (d) Gaoyuan bridge due to Wenchuan earthquake (2008).

Pile supported bridges can fail in various modes as the surrounding soil liquefies in case of an earthquake. The various failure modes identified so far in the literature: (1) bending failure due to higher bending moment being exerted on piles due to laterally spreading soil and inertial load from the superstructure; (2) settlement failure due to settling of piles for mobilization of additional skin friction and end resistance; (3) shear failure due to high shear demand; (4) buckling failure due to higher superstructure load at the pile top and unsupported length in the liquefiable zone of soil and (5) failure due to effects related to the differential elongation of natural period of piers. 
Traditionally, piles are designed for bending to counter the effects of laterally spreading soil and that of the inertial load in case of liquefaction. The literature by Orense et al. [1], Kato et al. [2], Franke and Rollins [3] and the guidelines given in Caltrans [4] give a good account of how the laterally spreading soil affects the pile foundation of bridges and other structures. The shake table tests carried out in the studies [5-7] also demonstrated that higher bending moment due to the inertial load from the superstructure, kinematic load due to the laterally spreading soil or a combination thereof can cause plastic hinging in embedded piles. Further, the study by Ishihara and Yoshimine [8], Knappett and Madabhushi [9] explains about the excessive settlement of piles as a result of mobilization of skin friction and end bearing and due to the post-shaking down-drag settlement during soil liquefaction. The $t-z$ and $q-z$ curve prescribed by API [10] can be appropriately used to estimate the post liquefaction settlement of piles. Conversely, Bhattacharya and Tokimatsu [11] initially set out the criteria for pile foundations to avoid buckling failure in the event of liquefaction. In addition, the researchers [12-14] also set out the criteria for design of piles inculcating the buckling failure mechanism in liquefied soil. Recently, Wang et al. [15] presented a shake table study carried out to study the behavior of pile group supported bridge piers for the case of general scour in liquefied soil. The particular case of pile supported bridges and their vulnerability to failure in liquefied soil are explored in Mohanty et al. [16] and Mohanty and Bhattacharya [17]. In their recent study, it has been postulated that the middle piers of the pile supported bridges are particularly vulnerable to failure due to the effects related to the differential elongation of natural period of piers. Understandably, the pile supported bridges can become vulnerable to failure due to any of these aforementioned five failure mechanisms in case of liquefaction in soil[17]. In this context, it is important to highlight the comparative study carried out about the caisson supported bridges and pile supported multi span bridges by Dammala et al. [18]. It shows that the caisson supported bridges, due to the very high foundation stiffness do not exhibit much change in their natural frequency when the surrounding soil liquefies.

\subsection{Aim and scope of the study}

The experimental work of Lombardi and Bhattacharya [19] showed that the natural frequency of pile supported structure reduces as the surrounding soil liquefies. The same analogy, if applied to the piled supports of a bridge, it can be inferred that they would exhibit a reduced natural frequency at full liquefaction. Interestingly, it has been found by Mohanty and Bhattacharya [17] through case studies that the natural frequency of individual piers of a bridge may reduce as much as by $50 \%$ at full liquefaction. In addition, it was suggested that consecutive pile supported piers of a bridge may exhibit differential elongation of their natural periods in the event of liquefaction, due to the natural river bed profile. As a result, all the piers will exhibit different natural frequencies at full liquefaction. As can be seen in Fig.2, in a typical river cross section, at full liquefaction, the unsupported length of the piled support increases more towards the center of a bridge as we move from abutment towards the center of the bridge. This makes the natural frequency of the consecutive individual supports at full liquefaction quite different from each other, which may amount to differential displacement demand for different piers of the bridge. To gain further understanding, a shake table experiment was carried out to verify the mechanisms behind the mid-span collapse of pile supported bridges and to observe the changes in the design parameters of the bridge due to liquefaction in soil. In particular, the aim of the experiment was to gain further understanding about the processes and mechanisms that controls the behavior of interest in 
relation to the collapse of middle and its adjacent spans of the bridge in the event of liquefaction.

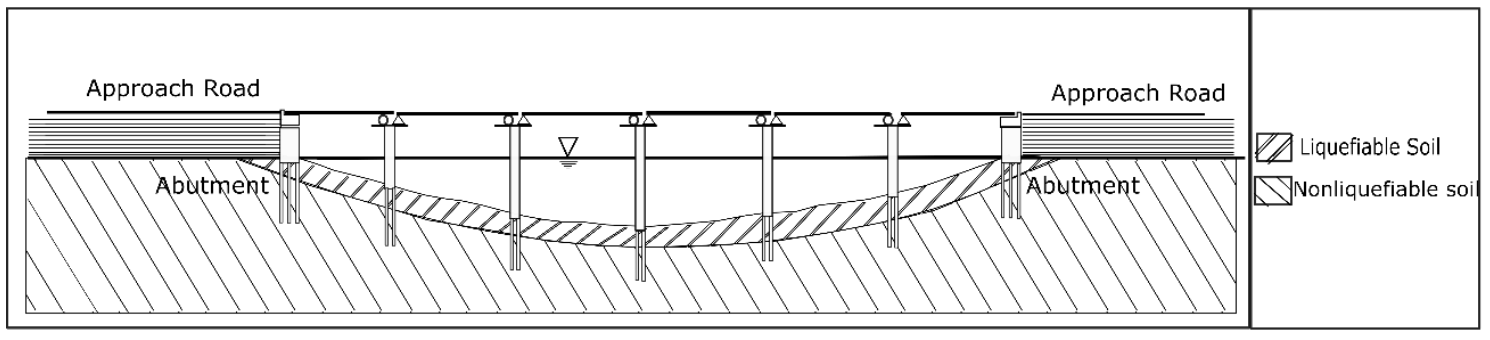

Fig. 2 Typical cross section of a river profile across a bridge

A typical pile supported scaled down model bridge is founded in a layered soil stratum, having liquefiable sandy soil layer overlying the non-liquefiable gravel strata. However, the sole aim of the paper is not to recreate the observed midspan collapse of the pile supported bridges, rather to verify the mechanisms which may lead to such kind of failure in those bridges. The mechanisms which have been addressed in this study are as follows:

(i) The change in natural frequency of the piled supports of the bridge due to liquefaction in soil.

(ii) The change in lateral displacement and bending moment of the pile, as a result of change in its natural frequency.

Hence, this study has following objectives:

(1) Investigate the natural frequencies of individual piled supports of a typical scaled down bridge before and after liquefaction

(2) Examine the impact of the reduced natural frequencies of the piers on their design parameters, e.g. bending moment and lateral displacement

(3) Study any further changes in other dynamic properties of the bridge due to liquefaction.

The paper is structured in the following way:

1) In section 2, the shake table experiment carried out at Institute of Engineering Mechanics (IEM), China Earthquake Administration, China is described. The geometry, dimensions, material properties of various components of the model bridge are given. The methodology of the experiment is described in this section as well.

2) In section 3, the data collected through sensors are presented and analyzed.

3) Lastly, the conclusions are drawn based upon the results and observations of the shake table experiments in section 4. 


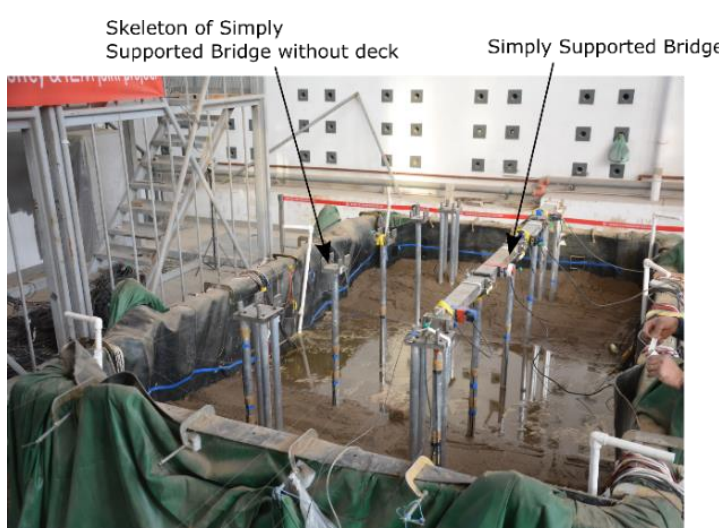

(a)

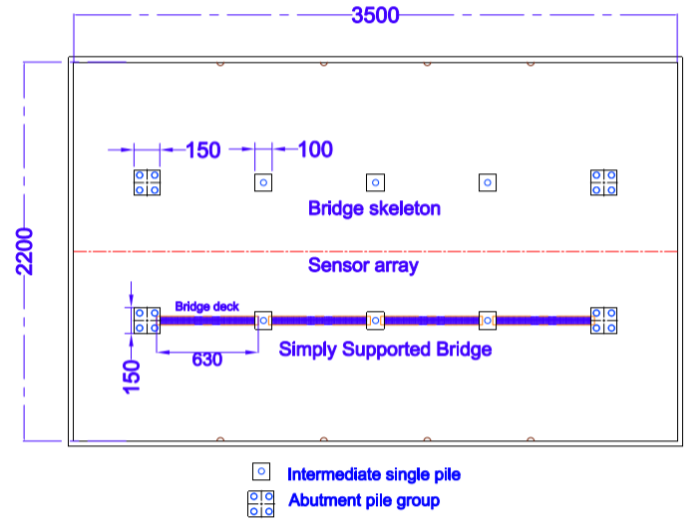

(b)

(c)

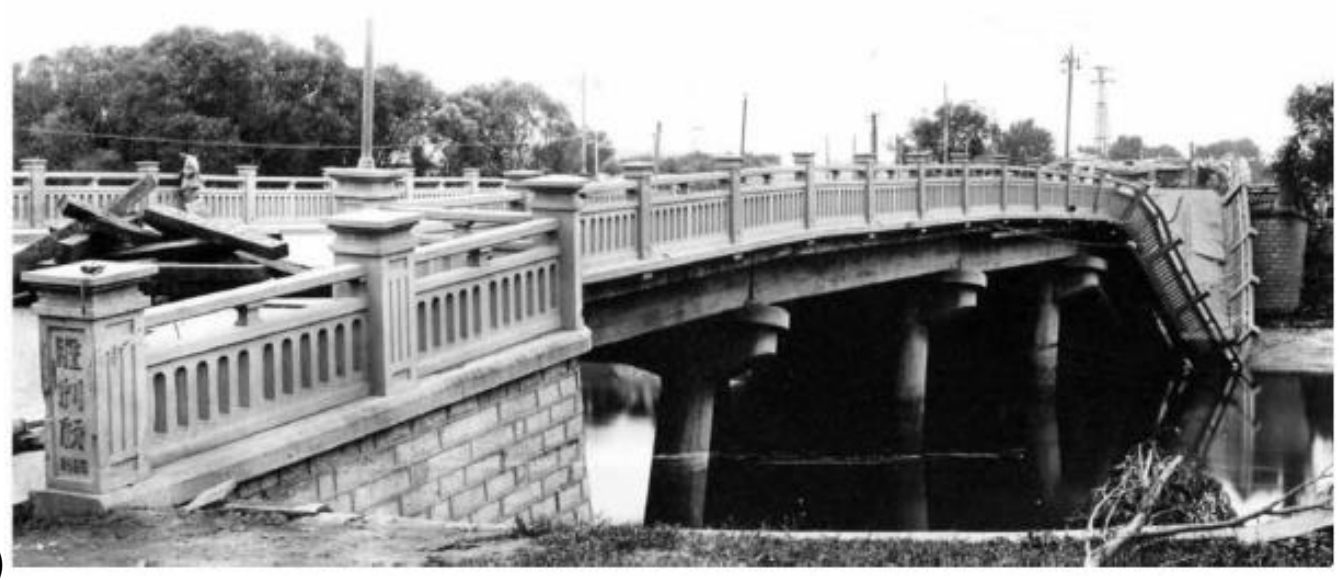

Fig. 3 Scaled down model bridges during the test (a) Picture of simply supported model bridge and the bridge skeleton used for the test, (b) Schematic diagram of the plan for the test set up (all dimensions are in $\mathrm{mm}$ ) and (c) Collapse of Shengli bridge, China during 1976 Tangshan earthquake.

\section{Details of shake table test:}

Shake table tests were carried out on a $5 \mathrm{~m} \times 5 \mathrm{~m}$ shake table facility at Institute of Engineering Mechanics, Hebei, China. The shake table has 6 degrees of freedom (DoF) with a payload capacity of 30 tons, and the maximum overturning moment capacity of 80 ton.m. The maximum allowable stroke in the two horizontal directions ( $X$ and $Y$ ) is $\pm 500 \mathrm{~mm}$ each and in the vertical direction ( $\mathrm{Z}$ ), it is $\pm 200 \mathrm{~mm}$. The maximum acceleration achievable in the horizontal direction is $3 \mathrm{~g}$ and $2 \mathrm{~g}$ with the bare table and full payload respectively. The shake table can generate the desired sine wave, random and earthquake time history. The operational frequency of the shake table is $0-100 \mathrm{~Hz}$.

In the test tank used for this study (laminar shear box in this case), two scaled down straight bridge models were constructed. One of the models was a simply supported bridge with the bridge deck on top of it and the other one was a bridge skeleton without any deck on the top (see Fig.3(a) and (b)). There was no bearings placed between the decks and the piles. It was intentionally done to eliminate any effect of the bearings on the overall vibration of the bridge supports, so that the effect rendered due to the liquefaction of soil can be solely studied. The analysis of the bridge skeleton is outside the scope of the present work and hence, all the 
construction details and the analysis presented in this study hereon will be about the simply supported bridge with deck only. The design of piled bridge for this study is inspired from the Shengli bridge of China, which collapsed during 1976 Tangshan earthquake. The picture of collapsed Shengli bridge can be seen in Fig. 3(c).

\subsection{Laminar shear box (test tank):}

All the tests were carried out inside a rectangular laminar shear box of $3500 \mathrm{~mm}$ long $\times 2200$ $\mathrm{mm}$ wide $\times 1700 \mathrm{~mm}$ deep (see Fig.3 and Fig.4). This laminar shear box has been used for liquefaction tests at various laboratories in China extensively and hence, its function has not been validated by further experiments during this study. Earlier, Su et al. [20] had employed this container for the study of soil-pile-quay wall system in liquefying soil and the same can be referred for further details of the test tank.

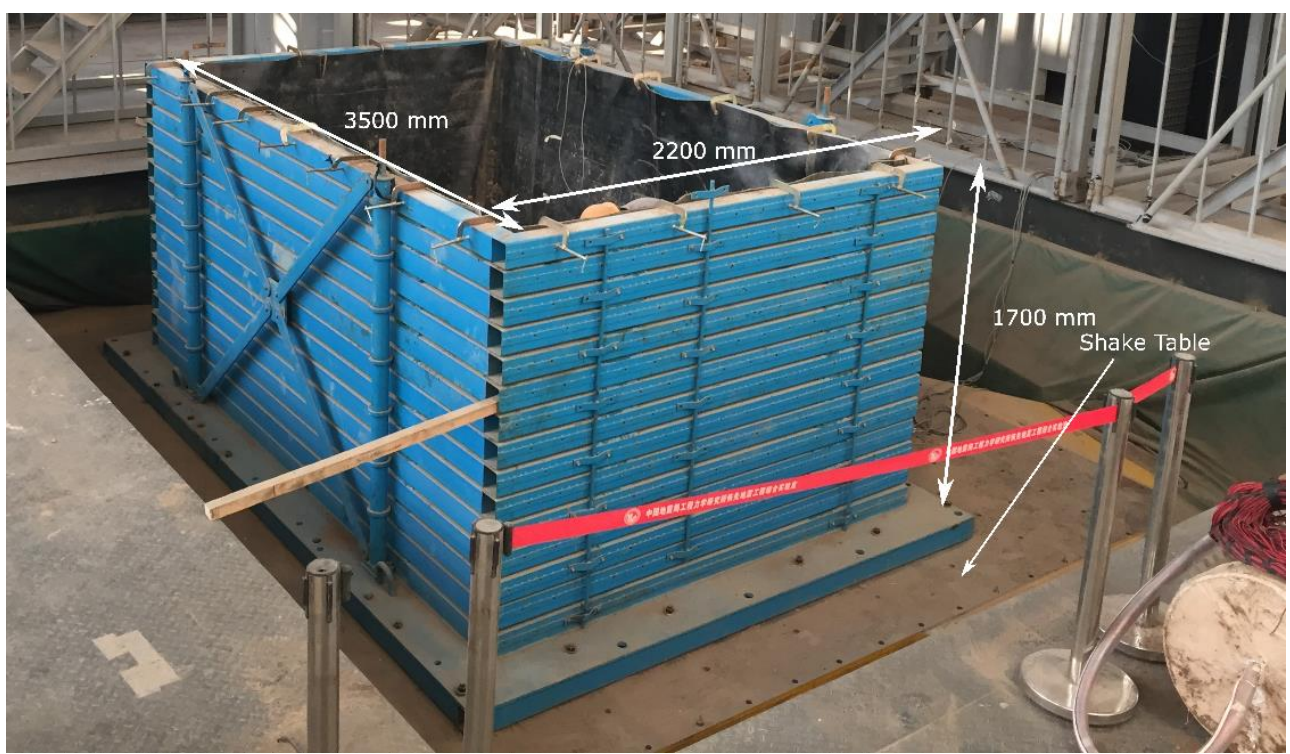

Fig. 4 Laminar shear box used for the test at IEM, Hebei, China

\subsection{Physical model details:}

The shake table test was carried out to mimic a typical river crossing bridge with the sloping riverbed profile and the river channel. The soil profile in the model test consisted of $1350 \mathrm{~mm}$ thick sloped ground, like a river profile as shown in Fig. 5, having the liquefiable loose sand layer overlying the non-liquefying dense gravel layer. The thickness of the top loose sand layer was $750 \mathrm{~mm}$ throughout the length of the test tank, sloping gently at an angle of $12^{\circ}$. This model ground was carefully prepared so as to represent the pile behavior in both the laterally spreading (sloping) and liquefied level ground. The thickness of the bottom gravel layer was varying to prepare the sloping bed for the overlying sand layer. All the piles were fixed to the bottom wooden board to simulate the scenario that the piles are embedded in nonliquefiable dense layer and to eliminate the effect of settlement of piles during soil liquefaction. 


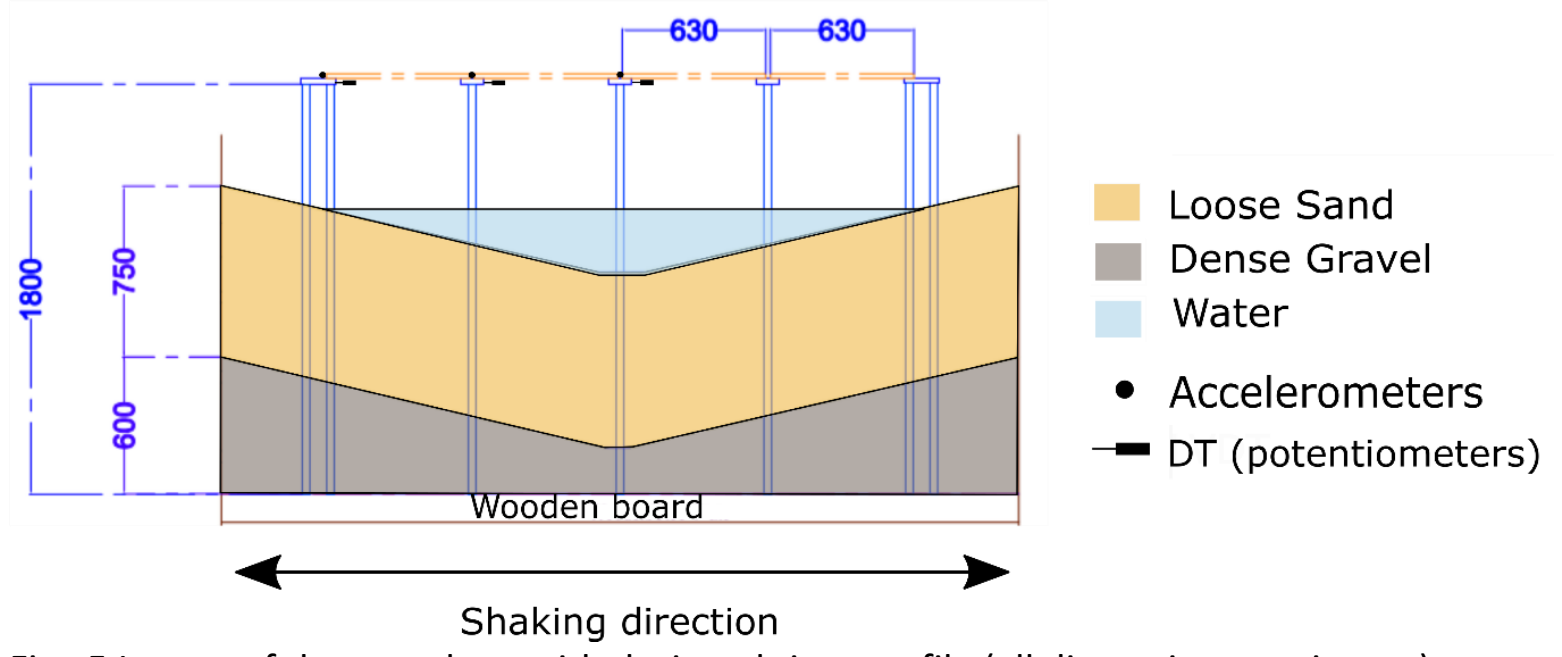

Fig. 5 Layout of the test along with designed river profile (all dimensions are in $\mathrm{mm}$ )

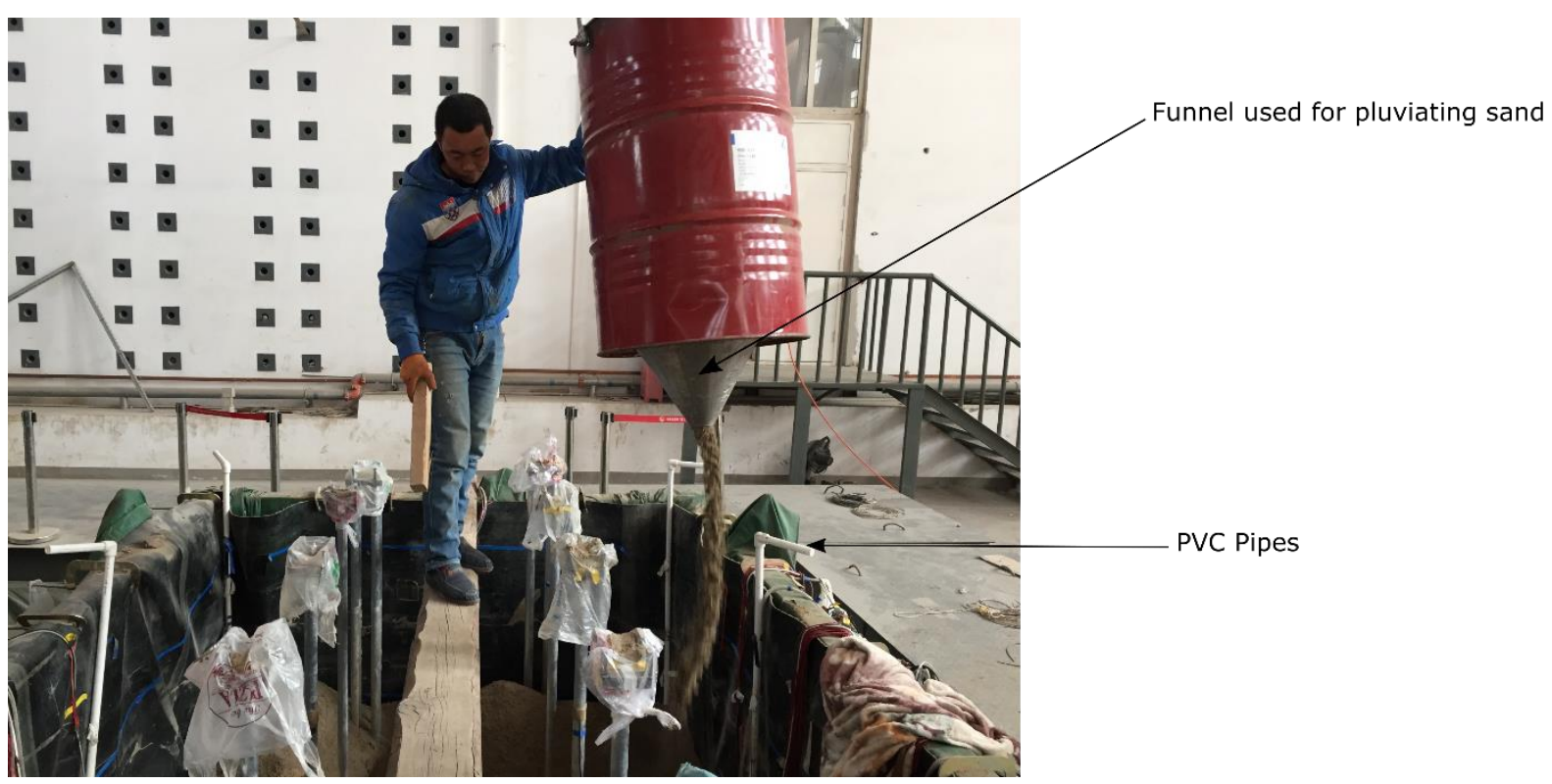

Fig. 6 Photograph of preparation of the sand layer in the test and PVC pipes being used to put the water inside

Two scaled down straight bridge models were constructed inside the test tank for the test. There were no bearings used for the bridge supports for this test. It was intentionally done to eliminate any effect of the bearings on the overall vibration of the bridge supports. There has been a number of work [21,22] on the seismic behavior of bridges, where shake table tests have been carried out without the presence of any bearing so that any additional dynamic effect of the bearings on the bridge behavior can be eliminated.

\subsection{Soil properties:}

The intention of the test was to get a layered soil stratum with the liquefiable soil overlying the non-liquefiable strata. As it is quite difficult to get a non-liquefied soil strata for the scaled down model tests due to its limitation of low confining stress, it was decided that a dense gravel layer must be used as the bottom non-liquefying layer to ensure that it does not liquefy during the test. 
The bottom gravel layer and the top sand layer were poured into the test tank in dry condition with the help of overhead cranes. The gravel was dropped from a height of $500 \mathrm{~mm}$ to maintain a constant density. After being put inside the tank, the gravel was tamped with a steel rod to make it denser. Once the dense gravel layer was prepared, the sand was pluviated from the top as shown in Fig. 6. The properties of the bottom gravel layer are given in the Table 1 and its grain size distribution is given in Fig.7(a). The gravel used for the test can be classified as poorly graded gravel (GP) as per the UCCS classification. The loose sand layer was prepared quite carefully by dropping the sand through a funnel of orifice of $60 \mathrm{~mm}$ and from a height of around $1200 \mathrm{~mm}$ (see Fig.6). The orifice diameter and the height of fall values for sand were determined as per the study by Gade et al. [23]. A very loose sand strata with relative density of $13 \%$ was achieved for the top sand layer by following the above methodology. Later the soil was saturated by putting the water through the bottom up methodology with the help of six equally spaced small diameter PVC pipes. The white small diameter PVC pipes used for putting water inside the tank can be seen in Fig. 6 . The small diameter pipes were specifically used so that the water discharge rate won't disturb the arrangement of soil particles near the water outlet nor create a piping effect inside the soil sample. Once the soil was saturated, the top sand strata settled down to achieve a final relative density of $25 \%$.

The overlying loose sand layer used for the test comprised of uniform graded sand, procured from the banks of Baihe river in China. The grain size distribution and the properties of the sand are given in Fig.7(b) and Table 1 respectively. It can be observed from the figure that the grain size of the sand falls well within the range of highly liquefiable soil as defined in the study [24]. The maximum and minimum dry unit weight for the sand was found to be 16.7 $\mathrm{kN} / \mathrm{m}^{3}$ and $13.5 \mathrm{kN} / \mathrm{m}^{3}$ respectively.

Table 1 Properties of the gravel and sand used for the test

\begin{tabular}{|l|l|l|l|l|l|l|l|}
\hline & $\begin{array}{l}\mathrm{D}_{10} \\
\mathrm{~mm} \text { ) (in }\end{array}$ & $\begin{array}{l}\mathrm{D}_{30} \\
\mathrm{~mm})\end{array}$ & $\begin{array}{l}\mathrm{D}_{50} \text { (in } \\
\mathbf{m m})\end{array}$ & $\begin{array}{l}\mathrm{D}_{60} \text { (in } \\
\mathbf{m m})\end{array}$ & $\mathrm{C}_{\mathrm{u}}$ & $\mathrm{C}_{\mathrm{c}}$ & $\mathrm{G}_{\mathrm{s}}$ \\
\hline $\begin{array}{l}\text { Underlying } \\
\text { gravel }\end{array}$ & 14 & 17.5 & 19.8 & 21 & 1.41 & 1.04 & \\
\hline $\begin{array}{l}\text { Overlying } \\
\text { sand }\end{array}$ & 0.1 & 0.17 & 0.2 & 0.24 & 2 & 1.2 & 2.65 \\
\hline
\end{tabular}




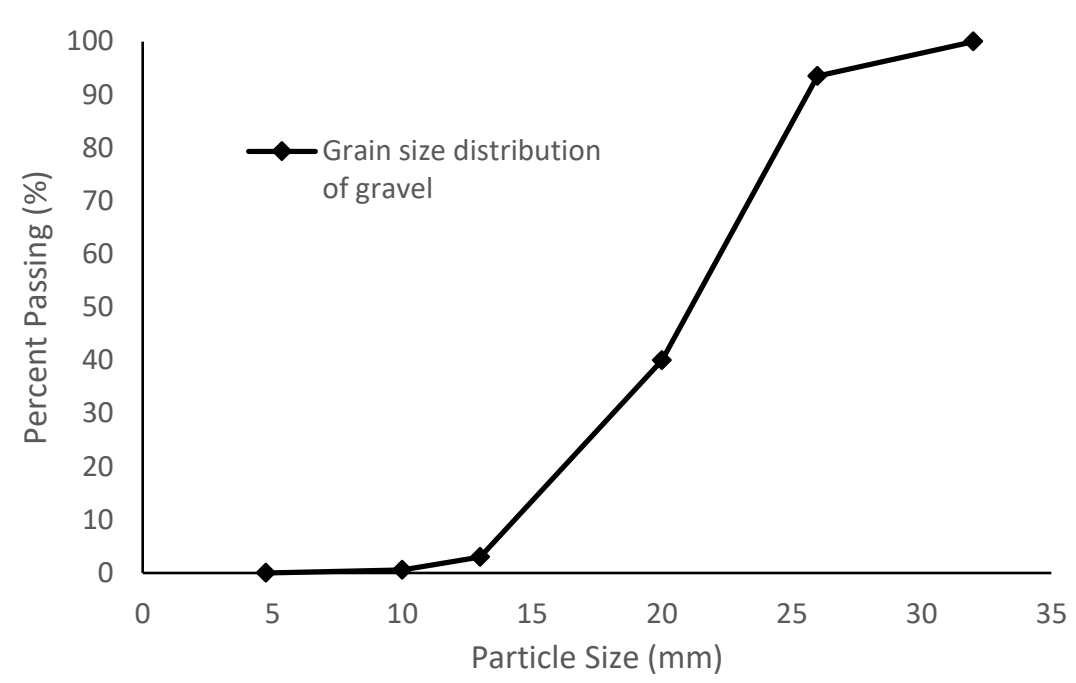

(a)

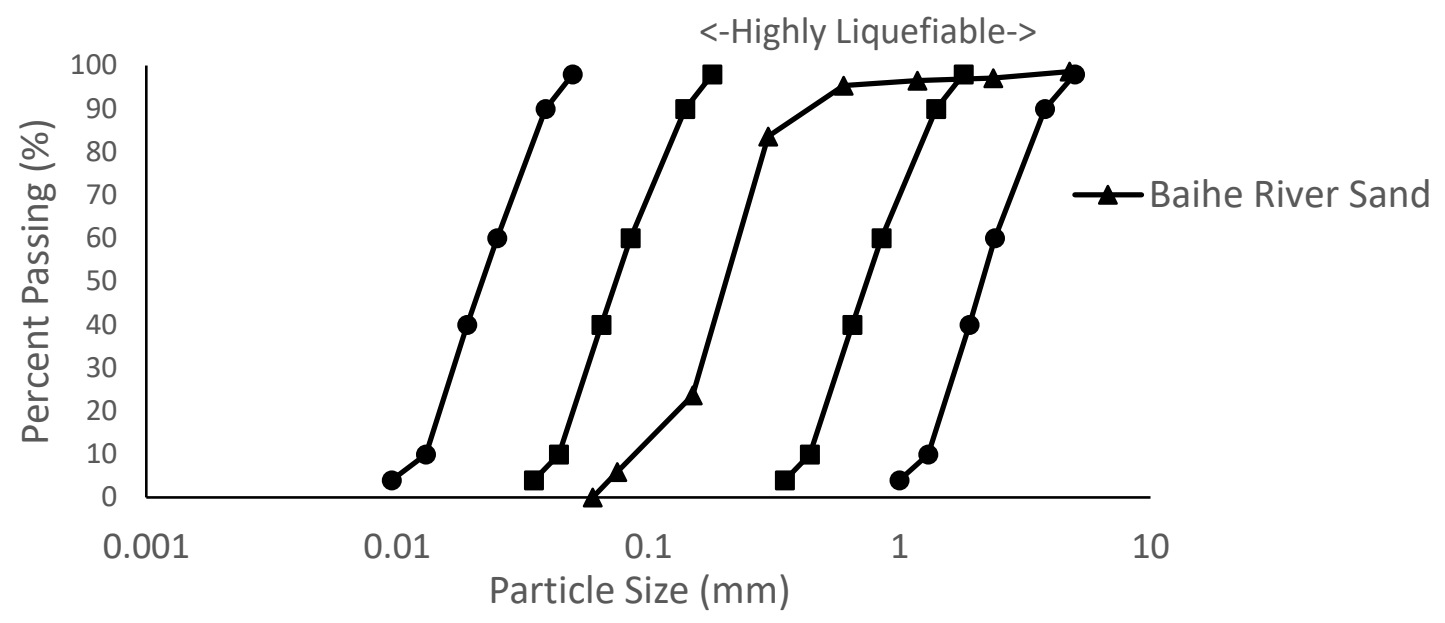

(b)

Fig. 7 (a) Grain size distribution of gravel; (b) Grain size distribution of sand

The properties of the soil used for the model test have not been scaled down/ up as the liquefaction in soil is a large soil strain problem. Further the literature [12] also suggest that to replicate the prototype soil exactly, the soil for the model test may require extremely high compression treatment, which may inevitably vary the natural properties of soils, thereby reducing the potential of liquefaction.

\subsection{Model bridge details:}

Two model bridges were constructed side by side inside the test tank as shown in Fig. 3(b). One of the bridges was simply supported on piles and decks were rested on pile caps and the other bridge was the skeleton of this bridge without any deck on the top, so that the effect of inertial load can be distinguished from that of the kinematic load (see Fig.3). The analysis of the bridge skeleton is beyond the purview of this study to maintain the brevity of the paper. The actual prototype pile adopted for this study was that of Shengli Bridge of China (see Fig.3(c)), which collapsed in 1976 Tangshan earthquake. Further details of Shengli bridge can be obtained by referring to the literature[17].

The model bridge for this experiment had 3 intermediate supports and 2 abutments. The intermediate bridge supports were founded on single piles. The pile group of $2 \times 2$ was used for both the abutments to represent their higher lateral stiffness as compared to the 
intermediate piers. The bridge had uniform deck of $630 \mathrm{~mm}$ long with a mass of $17.60 \mathrm{~kg}$ each. The details of the piles, pile caps and decks are given in the next section.

\section{Pile and pile cap details:}

The $1800 \mathrm{~mm}$ long hollow piles of 6063 T5 aluminum alloy were used as the model piles for the test. In the experiment, before the soil strata construction, the piles were fixed to a wooden board at the bottom to maintain the fixity, so as to represent a pile being fixed inside a non-liquefiable stiff stratum as shown in Fig. 5. The outside diameter and thickness of the piles were $34.9 \mathrm{~mm}$ and $1 \mathrm{~mm}$ respectively. The material properties and the geometric dimension of the pile are listed in Table 2.

The piles of intermediate supports of Shengli bridge have been chosen as the prototype pile for the experiment. The details of Shengli bridge can be found in the study by Tang et al. [25] and [26]. The bridge had piles of diameter of $900 \mathrm{~mm}$ and did not have any pile cap in between the pier and the pile. Hence, the whole pier-pile system of the pile supported bridge is being represented as a whole pile in this study, with a pile cap at the top to represent the pier cap of the prototype bridge support. It can be easily understood by referring to Fig.3 (a) and Fig.5. The piles of bridge supports of Shengli bridge varied in length from 25 to $30 \mathrm{~m}$ along the bridge. The relevant scaling factors have been adopted for this experiment and these are listed in Table 2. It can be observed that the geometric dimension of the pile has been carefully chosen for the experiment following the scaling laws of lai [27]. Although it was not quite possible to adopt the exact values determined by the study of the mentioned literature, attempt was made to make the ratios as close as possible to the proposed scaling ratio, along with the intention of the observed phenomenon to be clearly manifested in the experiment. The $2 \times 2$ pile group was used for the abutments, whereas for the intermediate piles, single piles were used (see Fig.3). The abutment in this study was represented by a pile group to represent its higher lateral stiffness. As understanding the effect of earth pressure during the process of liquefaction and back rotation of abutment were not primary objectives of the present study, an abutment with wingwall and breast wall was not installed. Instead, it was represented by a $2 \times 2$ pile group. The piles were spaced 2.5 times the diameter apart from each other in case of the pile groups.

Table 2 Scaling ratios for 1-g shake table test:

\begin{tabular}{|l|l|l|l|l|}
\hline & $\begin{array}{l}\text { Model } \\
\text { dimensions }\end{array}$ & $\begin{array}{l}\text { Prototype } \\
\text { dimensions }\end{array}$ & $\begin{array}{l}\text { Scaling ratio } \\
\text { (proposed by } \\
[27])\end{array}$ & $\begin{array}{l}\text { Scaling ratio in } \\
\text { this study }\end{array}$ \\
\hline Length $(\mathrm{m})$ & 1.8 & 26 & $\mathrm{n}$ & 14.4 \\
\hline Density $\left(\mathrm{kg} / \mathrm{m}^{3}\right)$ & 2700 & 2400 & $\mathrm{n}_{\rho}$ & 0.88 \\
\hline Strain & 1 & 1 & $\mathrm{n}_{\varepsilon}$ & 1 \\
\hline Acceleration & 1 & 1 & $\mathrm{n}_{\mathrm{a}}$ & 1 \\
\hline $\begin{array}{l}\text { Flexural stiffness } \\
\left(\mathrm{N} . \mathrm{m}^{2}\right)\end{array}$ & 1041 & $5.6 \times 10^{8}$ & $\mathrm{n}^{5} \cdot \mathrm{n}_{\rho} / \mathrm{n}_{\varepsilon}$ & 540682 \\
\hline
\end{tabular}

The steel pile caps were used for all the piles and were rigidly fixed to piles with the help of 'ergo 1690' adhesive, a Methyl Methacrylate structural adhesive. The fixity of this joint was checked before the actual tests and the adhesive was found to be quite rigid to represent the 
joint as a fixed joint. The pile caps used for the single pile and pile groups were of dimension $100 \mathrm{~mm} \times 100 \mathrm{~mm} \times 25 \mathrm{~mm}$ and $150 \mathrm{~mm} \times 150 \mathrm{~mm} \times 25 \mathrm{~mm}$ respectively. The mass of the pile caps for single pile and pile group were $2.25 \mathrm{~kg}$ and $4.10 \mathrm{~kg}$ respectively.

Accelerometers (ACCS) and wire potentiometers (DTs) were connected at different pile caps to measure their acceleration response and lateral displacement during the tests. The straingauges were placed at various heights on the piles for estimating the bending strain and bending moments in the pile.

Decks:

The model decks were placed on the top of pile caps to mimic the interaction of the superstructure with the model piles, although no attempt was made to replicate the exact superstructure load of the prototype Shengli Bridge. Each of the simply supported decks were of size $630 \mathrm{~mm}$ long $\times 76 \mathrm{~mm}$ wide $\times 46 \mathrm{~mm}$ thick, having a mass of $17.60 \mathrm{~kg}$. For the simply supported model bridge, the gap between two consecutive decks was maintained at $40 \mathrm{~mm}$ as mentioned in the Fig. 8(a). The naming convention used in this study for various bridge supports are also given in Fig. 8(a); e.g. 1LAP, 1LP, 1CP, 1RP, 1RAP bridge support were named to represent Left Abutment Pile (LAP), Left Pile (LP), Central Pile (CP), Right Pile (RP), Right Abutment Pile (RAP) of Bridge 1. The photograph of the model bridge deck used for the test is given in Fig.8(b).

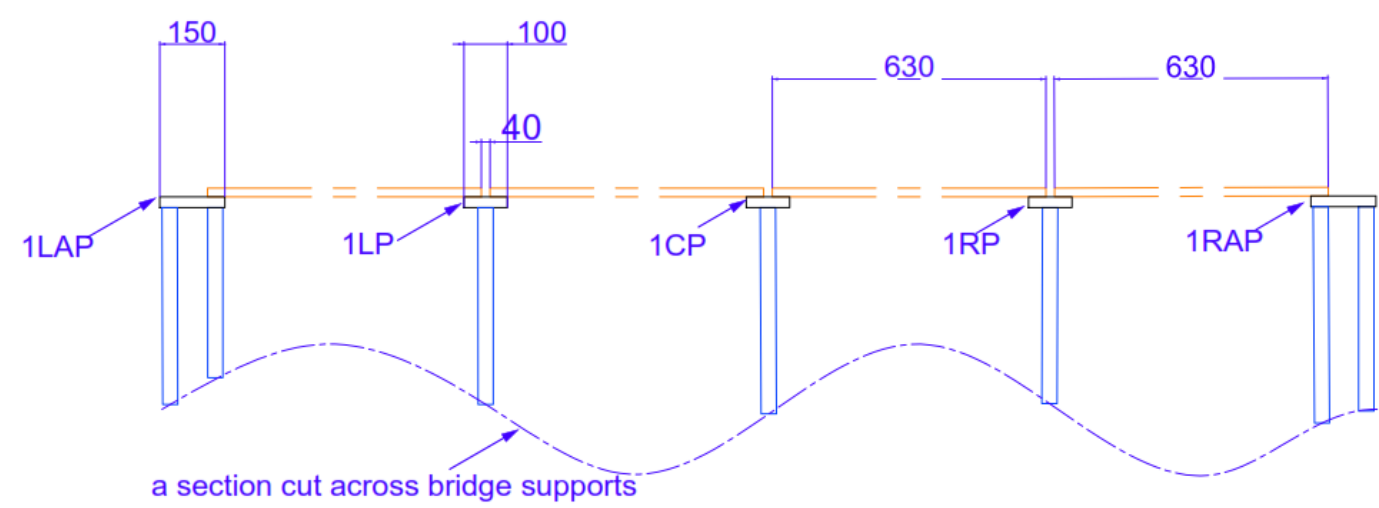

(a)

All dimensions are in $\mathrm{mm}$

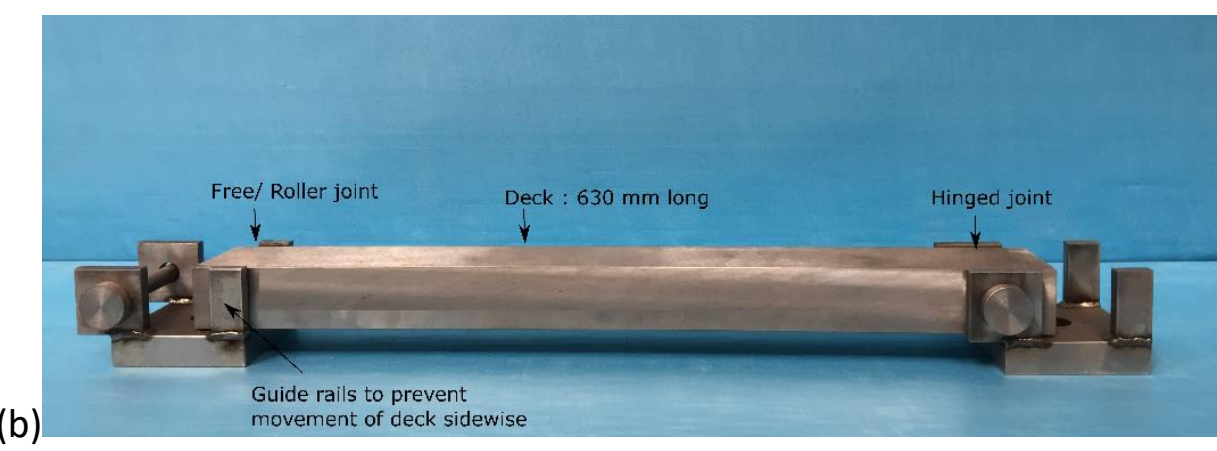

Fig. 8 (a)Geometric dimension of the deck and deck supports, represented through a section and naming convention followed for various bridge supports in this study; (b) Photograph of the model bridge deck 
The simply supported deck was designed in such a way that the superstructure load imposed on the intermediate piles was $19.85 \mathrm{~kg}$, which included the mass of the deck and that of the pile cap. This gave a Factor of Safety (FoS) of around 3 against the buckling failure. The decks were designed to be free at one end and hinged/pinned at the other end as shown in Fig. 8(b). Moreover, the grease was also applied at the bolt and nut arrangement near the hinged joint and also at the surface where the deck rested on the pile cap, so that the movement could be frictionless and effective.

\section{Base excitation:}

The input motion consisted of white noise signals having bandwidth frequency ranging from 0 to $50 \mathrm{~Hz}$ with four levels of acceleration, i.e. $0.035 \mathrm{~g}, 0.08 \mathrm{~g}$ and $0.12 \mathrm{~g}, 0.20 \mathrm{~g}$; applied through the shaking table. Each level of acceleration was applied for 80 seconds and was incremented to the next higher amplitude without stopping the shaking. The total duration of shaking was 320 seconds. The applied base input motion can be seen in Fig. 9(a). Each of the levels of acceleration is regarded as 'Phases of Test' in this study, i.e. Phase 1, Phase 2 etc.

\section{Observed response and analysis:}

Various accelerometers (ACCS) and pore pressure transducers (PPTS) were deployed inside the layered soil stratum to measure the acceleration and excess pore water pressure response of the soil during the test (see Fig.9 (b)). These sensors were arranged in an array at the midsection of the soil container, which was equidistant $(400 \mathrm{~mm})$ from both the model bridges (see Fig. 3(b) and 9(b)), to represent the free field condition [28]. Some of the pore pressure transducers were also placed on the sides of the piles to measure excess pore water pressure in the near field condition (see Fig. 9(c)). The data acquisition rate was fixed at $200 \mathrm{~Hz}$.

Further, the acceleration responses of different piles were monitored with the help of accelerometers mounted on the pile caps (see Fig. 9(c)). Wire potentiometers were also used at the pile caps to measure their lateral displacement during the course of motion. In addition, seven strain gauge pairs were used at different heights of three of these piles, $1 \mathrm{CP}, 1 \mathrm{LP}$, and one of the piles of abutment 1LAP to measure their bending moment during the test (see Fig. 9(d)). All these sensors were calibrated under standardized procedure before the test.

The soil container was shaken with white noise motion of increasing amplitude as shown in Fig. 9(a) without stopping in between. It could be observed that after the second phase of test, i.e. during the white noise motion of $0.12 \mathrm{~g}$ magnitude, the water started coming to the surface through formation of various cracks and sand boils due to liquefaction (see Fig.10). Some cracks also got formed near around the piles, through which the pore water started coming to the ground surface (see Fig. 11). Further, the soil in the sloped profile of river bed was observed to undergone lateral spreading and the overall thickness of the model ground was reduced to $1050 \mathrm{~mm}$ at the end of test. 


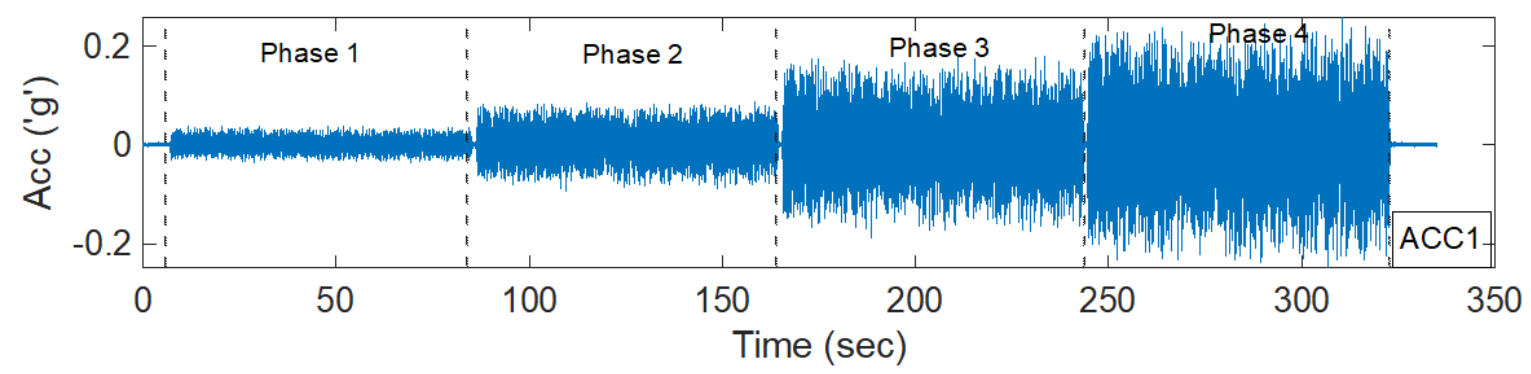

(a)

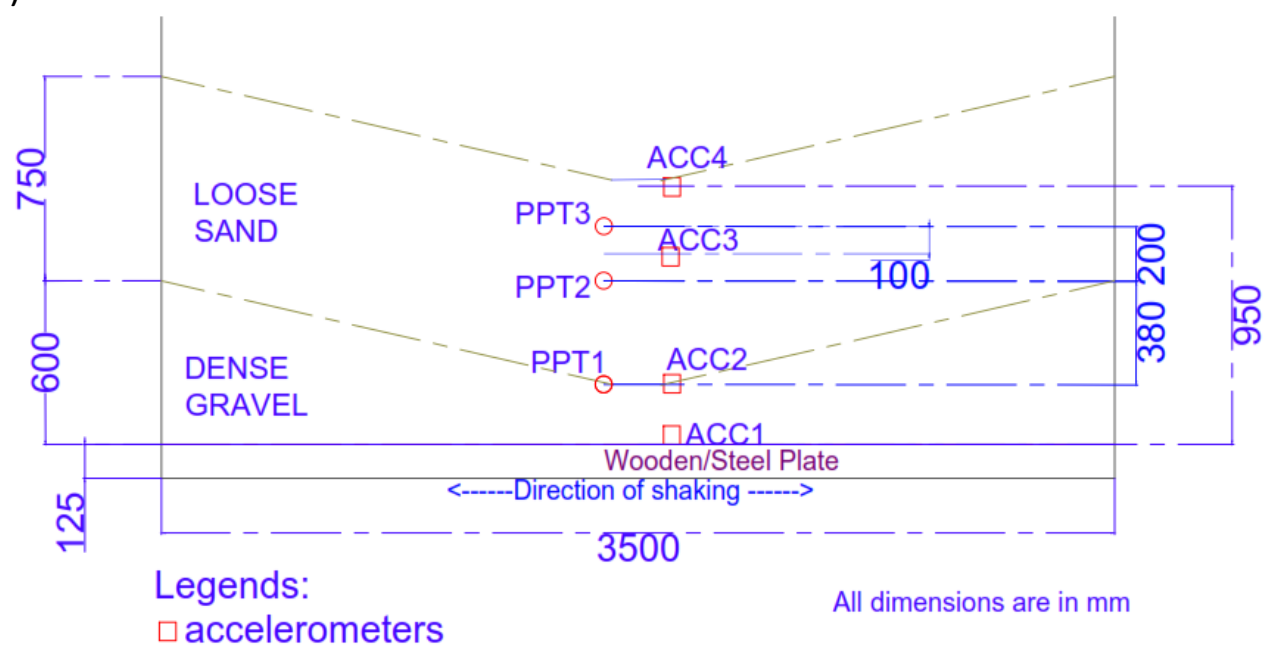

o pore pressure transducers

(b)

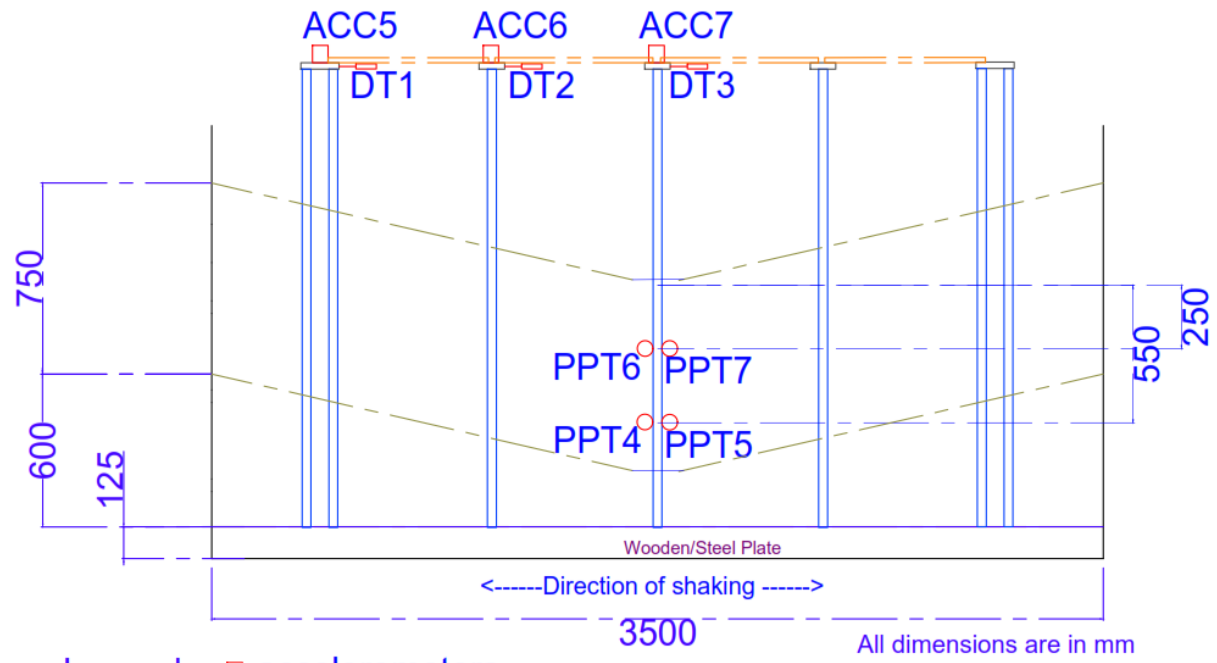

Legends: $\square$ accelerometers

o pore pressure transducers

$\rightarrow$ DT (potentiometer)

(c)

- Deck 

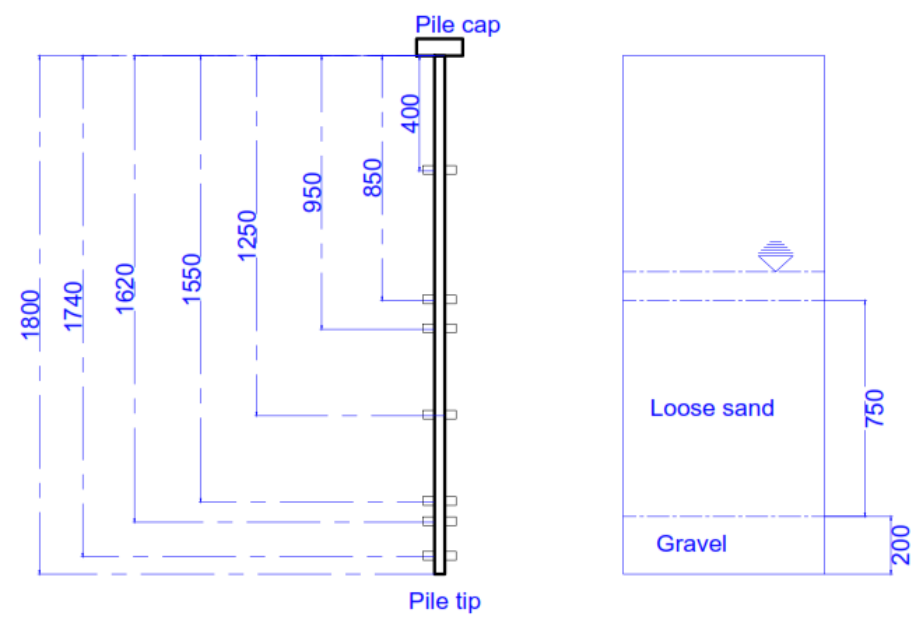

(i)

$\square$ Strain Gauge
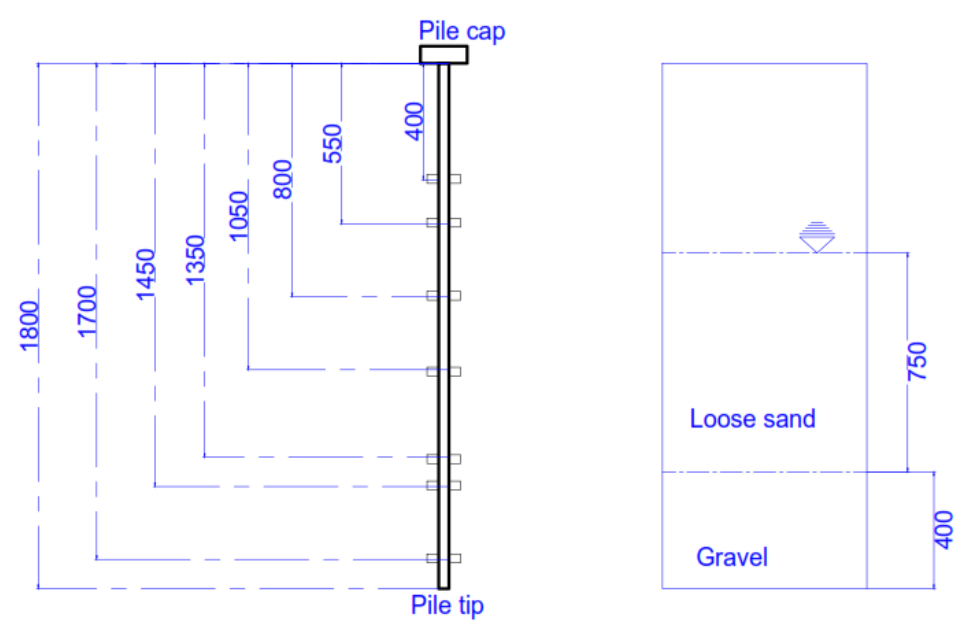

(ii)
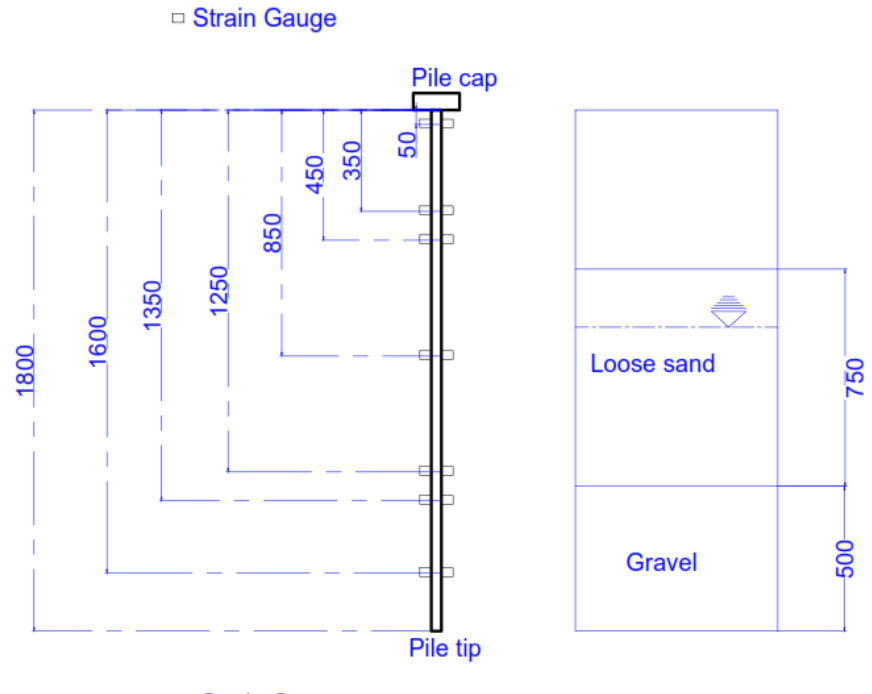

(iii)

$\square$ Strain Gauge

Fig. 9(a) Input motion given to the shake table; (b)Layout of the sensors placed in central array inside the soil ; (c)Layout of sensors placed along with piles; (d) Layout of strain gauges: (i) $1 \mathrm{CP}$, (ii)1LP, (iii) 1LAP. 


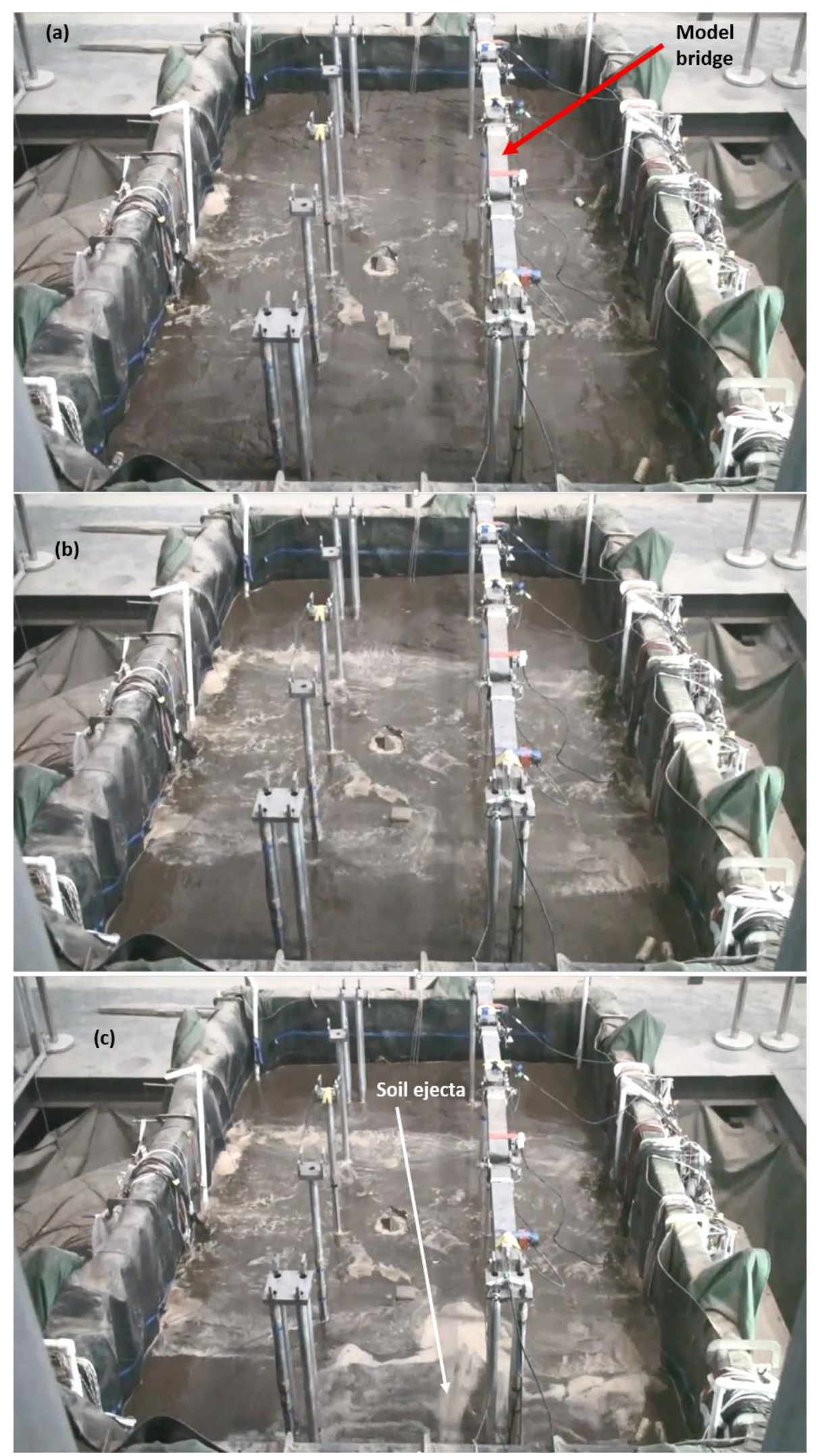




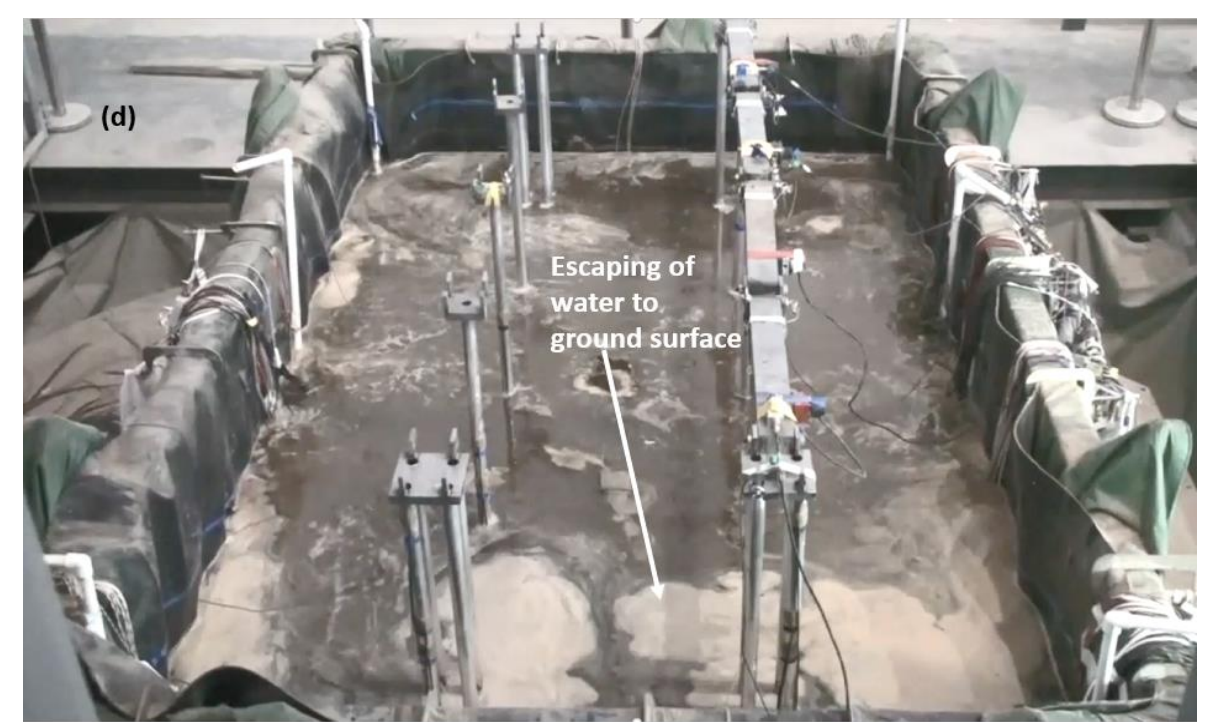

Fig. 10 Model soil and bridges at different phases during Test: (a) Just after Phase 1; (b) Just after Phase 2; (c) Soil ejecta to the top surface during $\mathrm{t}=170$ to 186 seconds (during transient phase); (d) After Phase 3

(a)

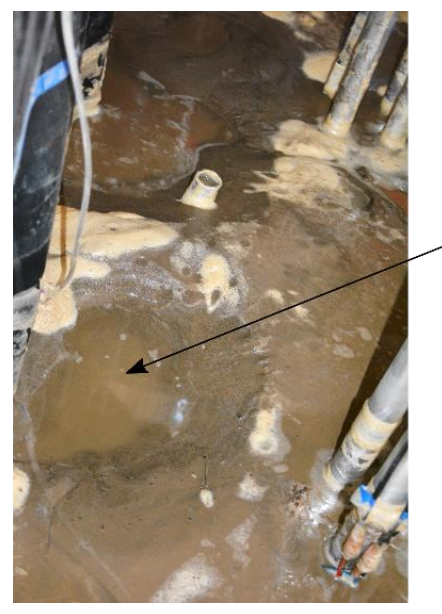

Formation of sand boils on ground surface (b)

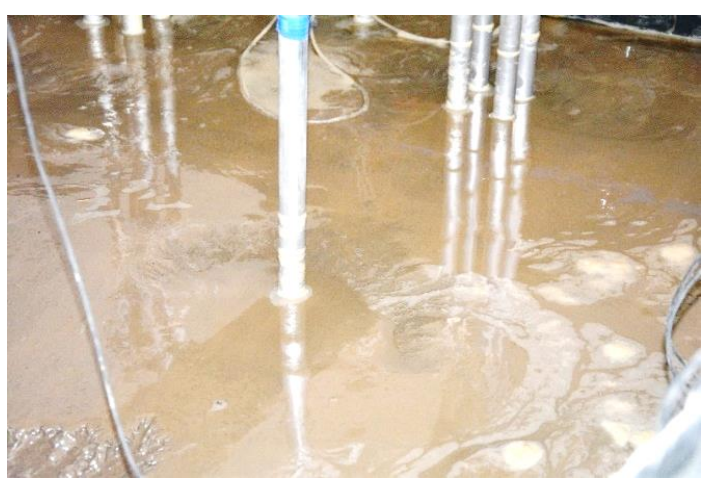

Fig. 11 (a) Formation of crack on the ground surface through which water rose up to ground surface; (b) Fomration of cracks/sandboils near the piles 

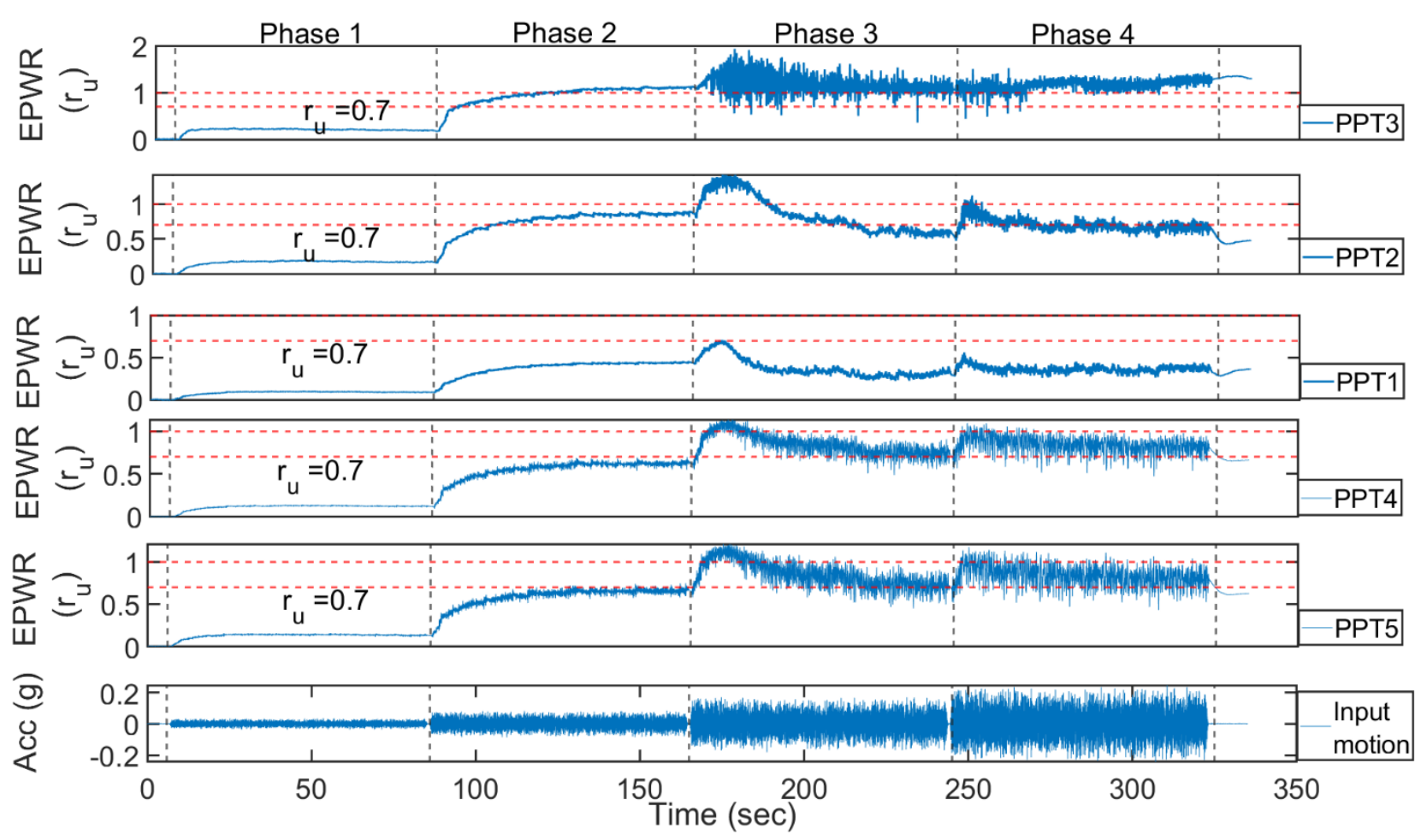

Fig. 12 Pore water pressure at different elevations inside the soil along with time history of the input motion given to the table

\subsection{Pore pressure response:}

The pore pressure transducers (PPT) were arranged inside the layered soil strata at different heights to measure the rise in excess porewater pressure in response to the motion given to the soil tank through the shake table. The layout of the arrangement of the pore water pressure transducers inside the soil is given in Fig.9(b) and 9(c). The pore pressure transducers PPT1, PPT2, PPT3 (see Fig.9(b)), PPT4 (see Fig. 9(c)) were placed at a depth of $730 \mathrm{~mm}, 350 \mathrm{~mm}$, $150 \mathrm{~mm}$ and $550 \mathrm{~mm}$ from the model ground surface inside the soil container before the shaking was started. The excess pore water pressure at four different heights below the model ground surface are given in the Fig.12 in terms of excess pore water pressure ratio $(E P W R)$, along with the input motion. The excess pore water pressure ratio (abbreviated as $E P W R$ in the figures). at a particular PPT location is defined as follows.

$\mathbf{r}_{\mathbf{u}}=\frac{\Delta u}{\sigma_{v 0}{ }^{\prime}}$

Equation 1

where $\Delta \mathrm{u}$ is the recorded variation of pore water pressure at a depth where the PPT was placed before shaking; and $\sigma_{\mathrm{v} o}$ is the initial effective overburden stress at that depth.

It is of utmost importance to understand that the pore pressure transducers may settle during the process of liquefaction as the soil settles down. Therefore, the pore pressure ratio $\left(r_{u}\right)$ can be seen being slightly greater than 1 in Fig. 12 for some of the PPTs. Consequently, precise estimation of excess pore water pressure ratio $\left(r_{u}\right)$ is quite challenging. Therefore, for all practical purposes, the soil was assumed to be liquefied for pore pressure ratio $\left(r_{u}\right)$ greater than 0.7 . It can be observed that the excess pore water pressure started increasing due to the increasing magnitude of the white noise motion, because of the undrained loading. 
Further, the soil at shallower depth attained higher pore water pressure earlier than the soil particles, which are at a greater depth inside the soil tank. The soil near PPT3 and PPT2 started liquefying at around 120 seconds, whereas the soil near PPT4 started liquefying at 160 seconds.

It can be observed that the pore pressure ratio $\left(r_{u}\right)$ for the PPT4, which is placed at $550 \mathrm{~mm}$ below the ground surface attained its highest value of unity due to the white noise motion of amplitude of $0.12 \mathrm{~g}$. But soon after near around at $\mathrm{t}=186$ seconds, it reduced to a value of 0.65-0.7. The pore water was also observed to have come out to the model ground surface through the sand boils during this phase of test (escaping of water to ground surface can be seen in Fig. 10(c) and (d)). Thereafter, the pore pressure ratio increased to a value of 1 during the $4^{\text {th }}$ phase and it remained at a steady value of 0.8-0.9 after reducing from unity for the rest of the input motion. Hence, for all practical purposes, it has been presumed that overlying loose sand liquefied upto a depth of $550 \mathrm{~mm}$ from the model ground surface during this 160186 second duration. For the rest of Phase 3 and Phase 4 of test, the loose sand strata stayed in a state of partial liquefaction. It can also be seen from the accelerometer plots in Fig. 13, where the acceleration record of ACC3 during Phase 3 shows that the acceleration started decreasing as soon as the soil liquefied in Phase 3 . But soon after $t=186$ seconds (shown by red dotted line in Fig. 13), the acceleration started increasing. This issue is discussed in detail in the next section regarding accelerometers.

It can also be possible that the soil below the elevation of PPT4 may have liquefied. As there were no pore pressure transducers placed below the elevation of PPT4 in loose sand layer, it is assumed that this soil layer had liquefied up to $550 \mathrm{~mm}$ below the model ground surface (up to PPT4). Further, wherever 'full liquefaction' has been mentioned in this study, it is referred to the condition that the full liquefaction has happened upto the depth of $550 \mathrm{~mm}$ from the ground surface. It can be noticed that the excess pore water pressure started reducing as soon as the soil liquefied in $3^{\text {rd }}$ phase of the test. This can be attributed to the dilatancy and consequently strain hardening of the liquefying loose sand layer. Zeghal and Elgamal [29] attributed these spikes in pore water pressure during the liquefaction to strain hardening (dilatancy) of the liquefying layer. In addition, the drop in the pore water pressure of soil surrounding PPT4 can also be caused due to the opening and closing of the gap between the soil and the pile, during the cyclic motion of the soil-pile system [30].

It can also be confirmed from the readings of PPT1 (see Fig.12) that the bottom gravel layer remained non-liquefied throughout the test.

\subsection{Acceleration response:}

Three waterproof uniaxial accelerometers were used inside the soil, at the boundary of each of the soil layers as shown in Fig.9(b). The accelerometer ACC1 was rigidly attached to the bottom of the test tank, hence its time history represents the input motion given by the shaking table. The accelerometers ACC2 and ACC4 were being used at the midsection of top surface of gravel and sand layer respectively. Additionally, the accelerometer ACC3 was placed inside the loose sand layer, at a depth of $250 \mathrm{~mm}$ from the model ground surface. The acceleration time history of all these accelerometers are plotted with respect to time in Fig. 13. The acceleration record of $A C C 2$ shows that the acceleration of the gravel layer gets amplified during the whole of input motion as this layer does not get liquefied. This kind of behavior, where the non-liquefying layers amplifies the input motion has been reported in many studies [15,31]. This happens as the gravel layer does not liquefy, however it exhibits 
the behavior of a soft soil, where the input motion gets amplified. However, for ACC3, it can be observed that the acceleration of soil surrounding accelerometer was almost same as that of the input motion during the Phase 1 and Phase 2 whereas during Phase 3 , the acceleration started decreasing as soon as the soil liquefied. But soon after $\mathrm{t}=186$ seconds (shown by red dotted line in Fig. 13), the acceleration started increasing. This behavior is commensurate with the surge and the drop (peaks) in pore water pressure in PPT2 as shown in the previous figures. This can possibly be attributed to the dilation of liquefied soil at around $t=186$ seconds. This kind of behavior has also been observed in other studies [14]. The pore water pressure of PPT2, PPT3,PPT4 and the acceleration record of ACC3 are put together in Fig. 14 to have a clear understanding of the underlying mechanism.

Further, accelerometers ACC5, ACC6, ACC7 were placed on the pile cap of $1 L A P, 1 L P$ and $1 C P$ (see Fig. 9(c)) respectively to measure the acceleration response of the piled supports. The acceleration responses of different piled supports are plotted in Fig.15 along with the time history of the input motion (ACC1). It can be observed from the Fig. 15(a) and (b) that the accelerations observed at all these pile caps show higher or similar value as compared to that of the input motion before the liquefaction. But after the liquefaction (during and after the third phase of input motion), the acceleration at the pile caps did not increase much as compared to that of the input motion, which kept on increasing. The envelopes given in Fig. 15(b) can be noted for the same. As a result of progressive liquefaction, the input motion to the soil does not get completely transferred to the piles, which has been manifested in the Fig. 15 (a) and (b). Hence, after the advent of $3^{\text {rd }}$ phase of the test (complete liquefaction) and in the Phase 4, the motion transferred to the piles can be observed to be reduced further as compared to the input motion given to the soil.

The data recorded by the accelerometers placed on top of the piles were further used to estimate the natural frequencies of the piled supports at different intervals of time.
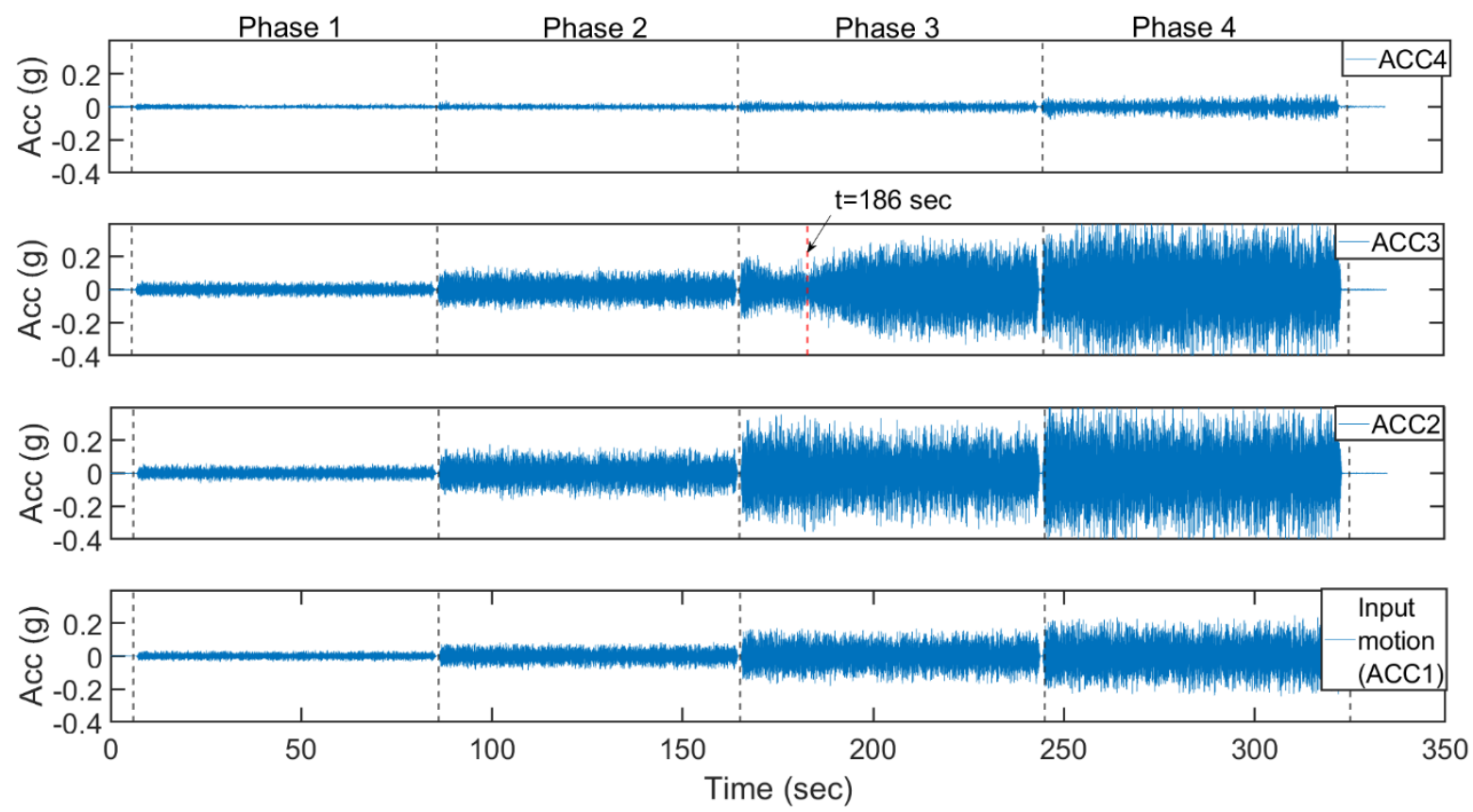

Fig. 13 Acceleration time history at different elevations inside the soil strata along with input motion 

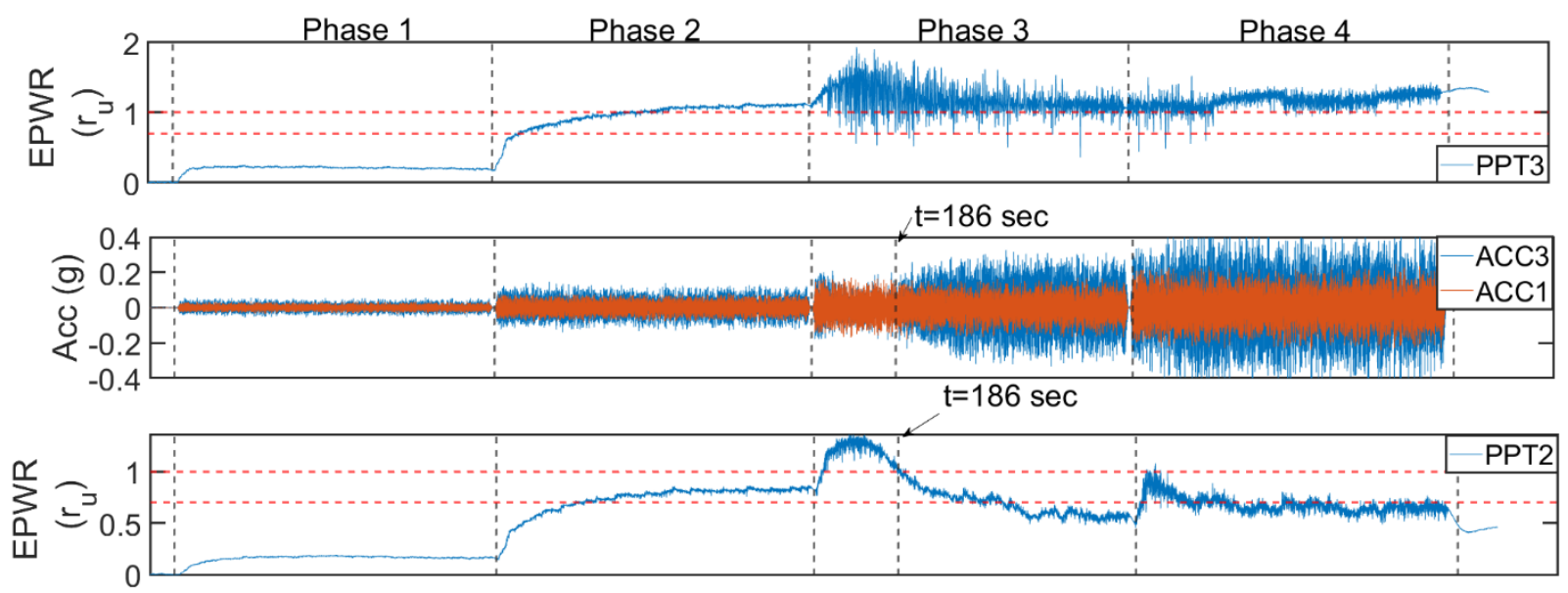

$\mathrm{t}=186 \mathrm{sec}$

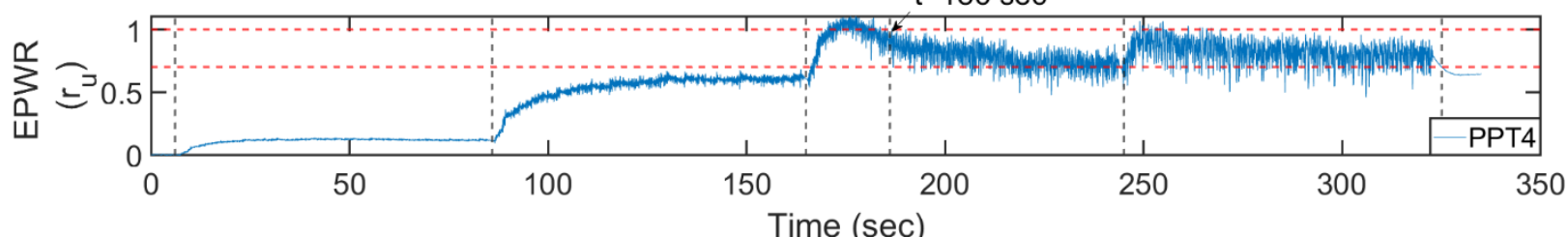

Fig. 14 Acceleration response of liquefied soil vis-à-vis its pore water pressure
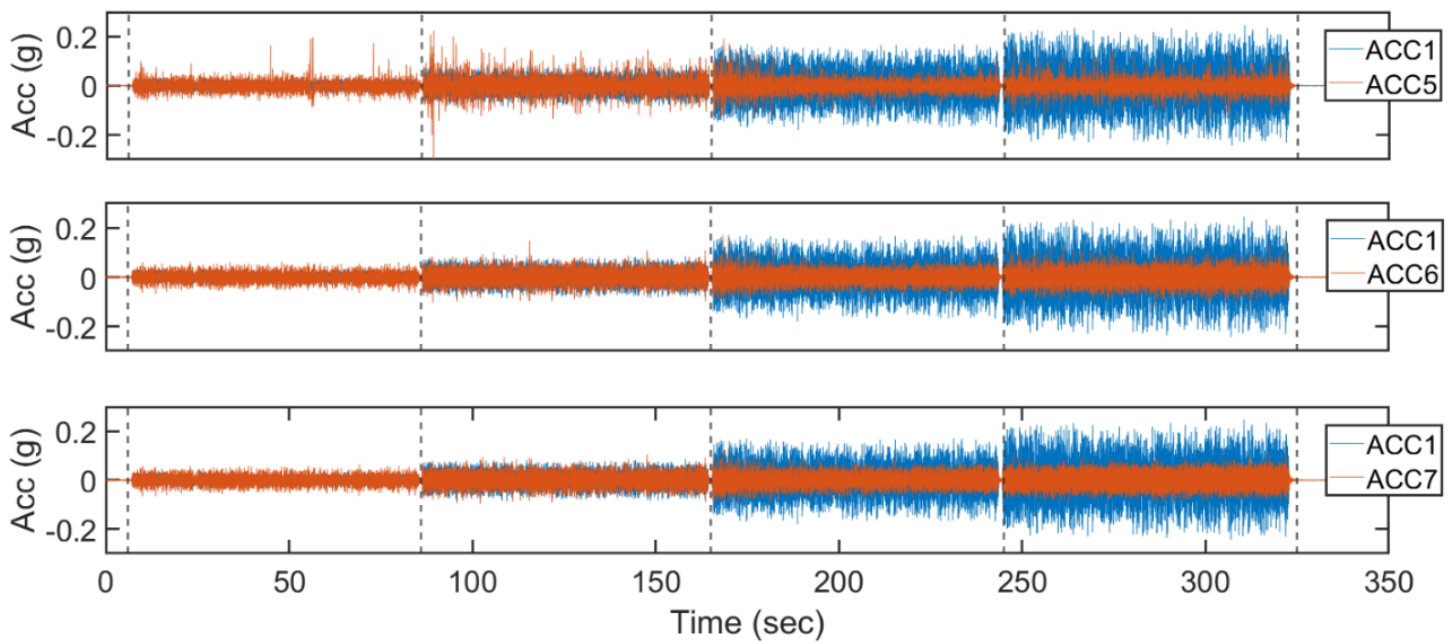

(a)

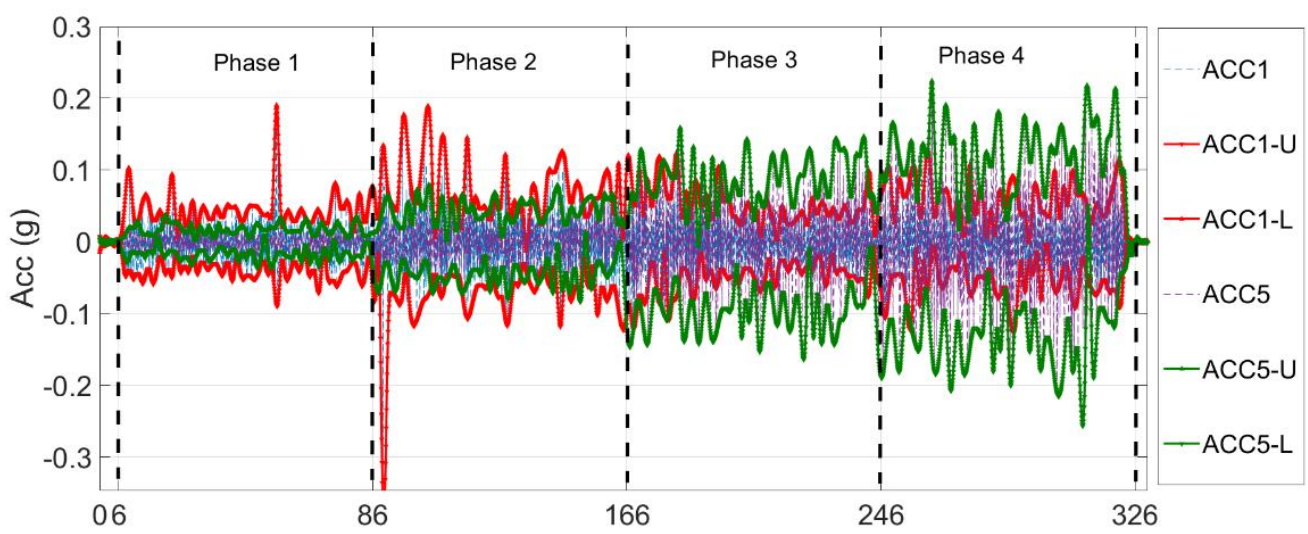

(b)

Time (sec)

Fig. 15 (a) Acceleration time history at different pile heads along with input motion; (b) Comparison of envelopes of acceleration response of ACC5 and ACC1 


\section{(A) Natural frequency of the system:}

The Fourier transform is widely used to find the frequency content of a signal obtained in the time domain. Based on the assumption of Fourier transform, this process is most appropriate for the signals, which are linear and periodic. However, for the signals which are nonlinear and non-periodic, this spectral analysis method cannot show the variation of the frequency content with respect to time. Hence, the time-frequency analysis is utilised to characterise a signal in both time and frequency domains. Various time-frequency analyses have been utilised till the date, e.g. spectrograms, wavelet analysis, Short Time Fourier transform (STFT) etc. In order to accommodate the sudden variation in the system frequencies in short time intervals, Short Time Fourier transform (STFT), introduced by Gabor [32] is often used. In STFT, the overall time history of the original signal is divided into smaller segments of fixed duration with each segment partially overlapping or not overlapping with the next one. Then Fast Fourier transform (FFT) of each of these smaller signals in each segment is conducted, giving the Fourier spectrum of each segment. These Fourier spectra can further be used to determine the fundamental frequency in each of these segments with the help of transfer functions.

This methodology of STFT has been used in this study to estimate the natural frequency of various piled support at different intervals of time. The transfer functions between different sets of signals recorded on different components of the model are used for evaluating the system response of the bridge supports. The transfer function can be evaluated through the Matlab command 'tfestimate'. The relationship between the input $x$ and output $y$ is modelled by a linear, time-invariant transfer function $H(f)$. It is assumed that in the frequency domain, $Y(f)=H(f) X(f)$. Hence, the value of $H(f)$ can be estimated by the following equation.

$\boldsymbol{H}(\boldsymbol{f})=\frac{\boldsymbol{P}_{\boldsymbol{y} x}(\boldsymbol{f})}{\boldsymbol{P}_{x x}(\boldsymbol{f})}$

Equation 2

where $P_{y x}$ is the cross power spectral density of $\mathrm{x}$ and $\mathrm{y} ; P_{x x}$ is the power spectral density of $\mathrm{x}$. The above methodology is used to estimate the system response of various bridge supports and is defined as follows:

1) System response of the abutment pile group $1 L A P$ is evaluated by finding out the transfer function between the measured acceleration at its pile cap (ACC5) and that of the input motion, given at the bottom of the soil tank (ACC1).

2) System response of the intermediate bridge supports having piles $1 L P$ and $1 C P$ are evaluated by finding out the transfer function between the corresponding accelerograms at their pile cap and that of the input motion.

This above methodology allows the estimation of natural frequency of the piled supports of $1 L A P, 1 L P$ and $1 C P$ at different intervals of time. For this process, the total time history of 320 seconds was divided into 44 sections; each of 7.5 seconds with no overlap between any two consecutive sections. It has been decided as per the following criterion:

1) This block of 7.5 seconds time duration was decided in such a way that all the modes of interest are sufficiently excited. Usually given a time window that is ' $T$ ' seconds long, the minimum frequency that can be resolved is $1 / T \mathrm{~Hz}$, for that time signal. Hence, with a signal length of 7.5 seconds, the minimum frequency that can be clearly resolved is $0.133 \mathrm{~Hz}$. As the signal frequency below $0.26 \mathrm{~Hz}$ is regarded as noise for the accelerometer data for this study, the signal length of 7.5 seconds can be aptly used for STFT. 
2) Further, as the soil-structure interaction behaviour in liquefied soil is a highly nonlinear problem, the time duration for each block (known as time resolutions) shall be such that the soil-pile system remains linear during that time; in other words, the transfer function shall be linear during that time. Once the complete input and corresponding output signals were divided into blocks of 7.5 seconds, the linearity of the transfer functions were verified with the help of MATLAB command 'isnlarx'.

Hence, each phase of the test has 10-11 blocks, each of 7.5 seconds duration and each of the block is named with an Roman number as suffix. For example, the first 7.5 seconds of Phase 1 is known as Block 1-I; the second 7.5 seconds of Phase 1 is known as Block 1-II; similarly the second 7.5 seconds of Phase 2 is known as Block 2-Il etc. So, Phase 1 will have 11 blocks: Block 1-I, Block 1-II, Block 1-III, Block 1-IV and so forth.

\section{(a) Central Pile (1CP):}

The natural frequency of central pile $1 C P$ at different intervals of time has been evaluated with the help of Short Time Fourier Transformation (STFT). It was found that the natural frequency of $1 C P$ was around $5.8 \mathrm{~Hz}$ during the Phase 1 of the test, which started decreasing in the subsequent phases of input motion and attained its lowest natural frequency of 1.96 $\mathrm{Hz}$ at around 170 seconds. It may have happened as the soil started liquefying progressively, the natural frequency of the bridge support started decreasing. The decrease in the natural frequency of pile $1 C P$ is presented in terms of the ratio of $f_{n} / f_{n i}$ (where $f_{n}=$ natural frequency of the pile at a particular block of the test; $f_{n i}=$ natural frequency of the same pile at first block of first phase of test) in Fig. 16 along with for other piled supports. It is of interest to note here that the natural frequency of $1.96 \mathrm{~Hz}$ was predominant for the time period of 165-172.5 seconds, just around the time when the top loose sand fully liquefied up to the depth of 550 $\mathrm{mm}$. Further, it can also be observed that the natural frequency of central pier started increasing to some extent thereafter. This can be attributed to the dilatancy and consequently strain hardening of the liquefying loose sand layer.

\section{(b) Abutment Pile (1LAP) and Intermediate Pile (1LP):}

Similarly, for the abutment $1 L A P$, its natural frequency was estimated from the transfer functions between the accelerogram of ACC5 and ACC1. It can be noticed that the natural frequency started decreasing as the soil started liquefying from the model ground surface. The abutment $1 L A P$ had the initial natural frequency of $6 \mathrm{~Hz}$, but it reduced by about $60 \%$ to its lowest value of $2.34 \mathrm{~Hz}$ at around 170 seconds, just about the time when central bridge support attained its lowest frequency. Moreover, the intermediate bridge support having pile $1 L P$ had the initial natural frequency of $5.9 \mathrm{~Hz}$ and it reduced to its lowest value of $1.96 \mathrm{~Hz}$ at around 170 seconds.

It can be observed that the abutment $1 L A P$ and the intermediate bridge supports having piles $1 L P$ and $1 C P$ had similar initial natural frequency during the first phase of loading, as the whole bridge started moving as one whole system. Due to the small value of displacement being applied and small inherent friction of the system, the whole bridge behaved as one single system during Phase 1 of input motion. It can be explained by the mode shape of the above mentioned three piles as given in Fig. 17. It can also be possible due to the 'deck to pile' interaction, where the presence of the stiff deck affects the movement of each of the piles. This effect has been explained in the next section.

But as the magnitude of acceleration of the white noise motion started increasing, the seismic shear force acting on each of the decks could overcome the inherent friction of the system 
and hence, all the piled supports started showing different natural frequencies. The central pile $1 C P$ exhibited the lowest natural frequency among all the instrumented piled supports at full liquefaction in the Phase 3 of the test. It may have happened as the maximum depth of liquefaction was achieved in this phase, rendering different lengths of piled support unsupported. As the central bridge support $1 C P$ had the maximum unsupported length of pile at full liquefaction, it could be observed that it also had the lowest natural frequency at the time of full liquefaction. It must be emphasized that in a prototype bridge, this difference in natural frequency of two consecutive supports at full liquefaction can be quite large, depending upon their respective soil supports. It is also of interest to note here that for all these monitored piles, the lowest frequency has been found for a time duration, hence the exact time of lowest natural frequency has not been found out.

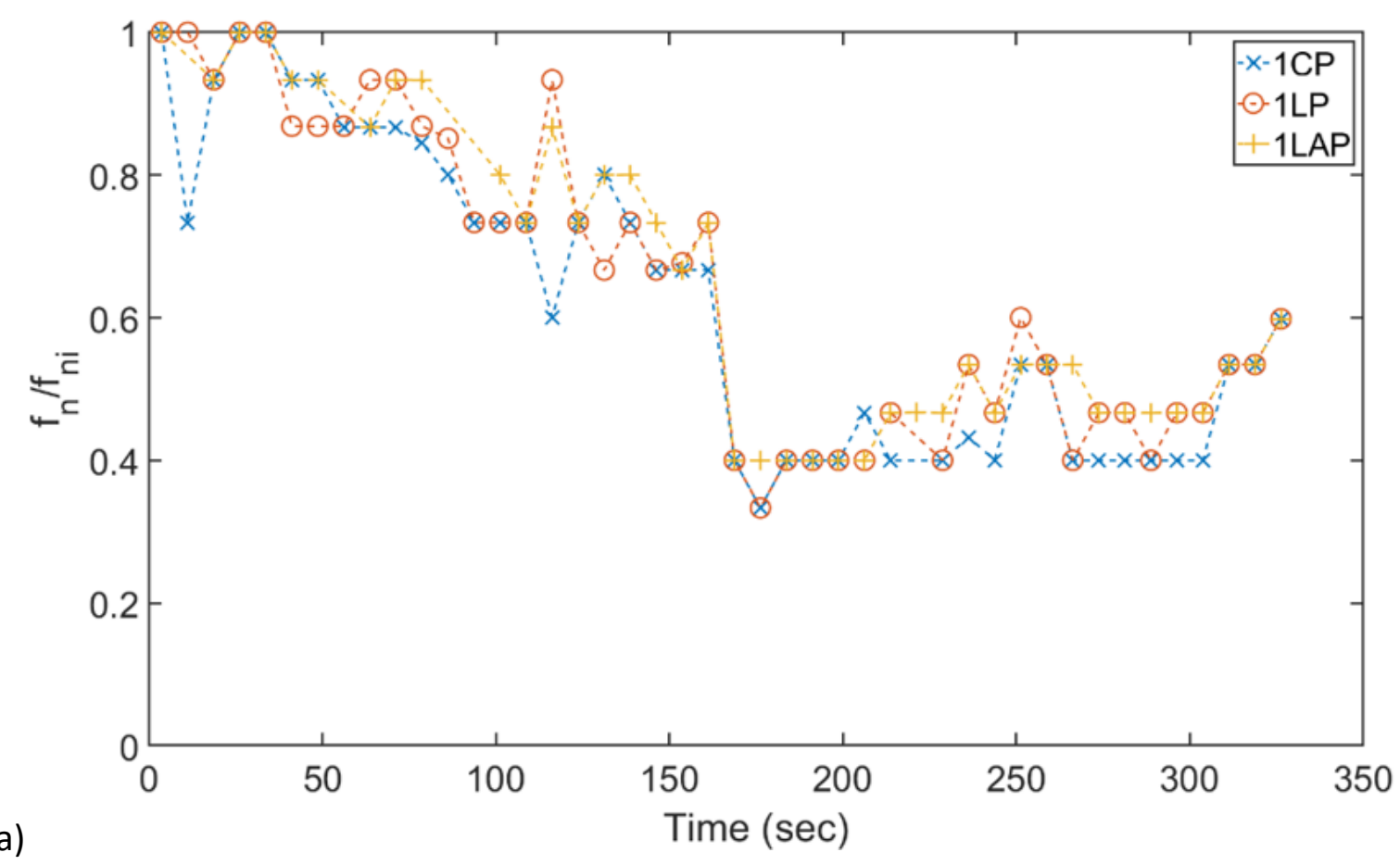

(a)

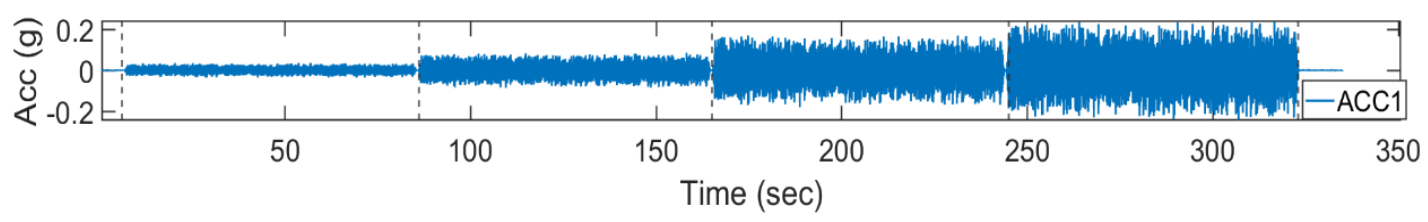

(b)

Fig. 16 Variation of natural frequency of various bridge supports during the test (a)Change of natural frequency of piled bridge supports; (b) Input motion;

Deck to pile interaction:

The presence of stiff deck sometimes makes the entire bridge to behave similar to one single system for different motions. In other words, the movement of various bridge supports gets coupled with the deck. This has been termed as 'deck-to-pile' interaction or 'coupling effect' in the literature by various researchers $[33,34]$.

To further illustrate this effect, before this test commenced, two sets of free vibration tests were carried out. In one of these sets of tests, dead loads equivalent of the superstructure load was kept on each of the pile caps securely. Hence, a dead load with a weight that of the model deck was put on the central pile and the intermediate piles $(1 C P, 1 L P$ and $1 R P)$, whereas a dead load with a weight equal to half of the model deck was put on the abutment bridge 
support (1LAP and 1RAP) for the free vibration test. Another set of free vibration test was done after putting the deck in place, on top of the pile caps. The Table 3 and 4 summarise the findings of the free vibration tests. It can be observed from Table 3 that all the piled bridge supports had significantly different natural frequencies at different soil fill conditions, i.e. without any soil, only with gravel, with both gravel and sand being filled up to its design height. In other words, they behaved as independent systems. But once the deck was placed on top of the pile caps, various bridge supports started exhibiting natural frequency close to each other (see Table 4).

Further, the mode shapes of different bridge supports were compared for different phases of the test and are given in Fig. 17, for insight into such interaction. The mode shapes of different bridge supports were estimated from the readings of the strain gauges and with the help of ARTeMIS Modal software. These mode shapes correspond to the deformation of pile at their natural frequency in the initial 10 seconds of each of the phases of the test. It can be seen in Fig. 17 (a) that the mode shapes of all the bridge supports were similar (sway) in the initial 10 seconds of Phase 1 of the test, as a result similar natural frequency was exhibited by all the bridge supports initially. It may have happened as the whole bridge system moved as a single system due to the inherent friction present at the free end of the decks, although all the arrangements to minimize such a force was done before the test. But as the magnitude of the input motion kept on increasing in the successive phases of the test, the lateral seismic shear acting on the decks could overcome the inherent frictional force of the system. Hence, they started showing different natural frequencies at different intervals of time. Further it can also be seen in Fig. 17(c) that the pile $1 L P$ and $1 C P$ had similar mode shapes for the initial 10 seconds of the Phase 3 of the test. Hence, both had the similar lowest natural frequency of the order of $1.96 \mathrm{~Hz}$ in the time duration of $165-172.5$ seconds of the test. Owing to the small scale of the model, the obvious difference between the lateral stiffness of the pile $1 C P$ ad $1 L P$ was found to be quite less to be manifested in their corresponding natural frequencies. It is quite interesting to observe that once the lateral spreading of soil got initiated in the Phase 3 and Phase 4 of the test, the mode shapes of the pile $1 L P$ and $1 C P$ turned out to be quite different from each other, as given in Fig. 17(d).

The deck to pile interaction can also probably be caused due to the absence of isolation bearings at the pile cap. But the presence of isolation bearing would have seriously alternated the behaviour of the system as already explained in the previous section 2.2 , which was quite unwarranted.

Despite this deck to pile interaction effect, the higher reduction in natural frequency was observed for piles with lower lateral stiffness. In such a scenario, in case of a protype bridge in liquefied soil deposits, the central piles do have the least lateral stiffness as compared to its adjacent piers, owing to the higher unsupported length of pile. Therefore, the natural frequency for the central pile will likely to be the least among its adjacent piers, due to liquefaction in soil. The implication of this effect on its lateral displacement and the bending moment has been discussed in the next section. 


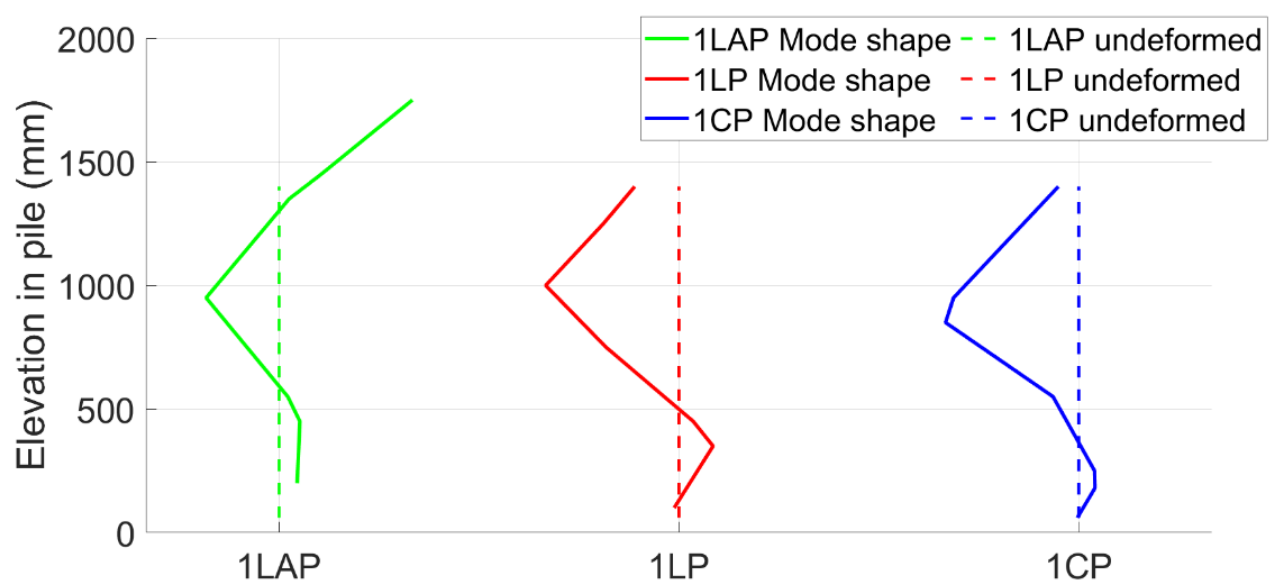

(a)

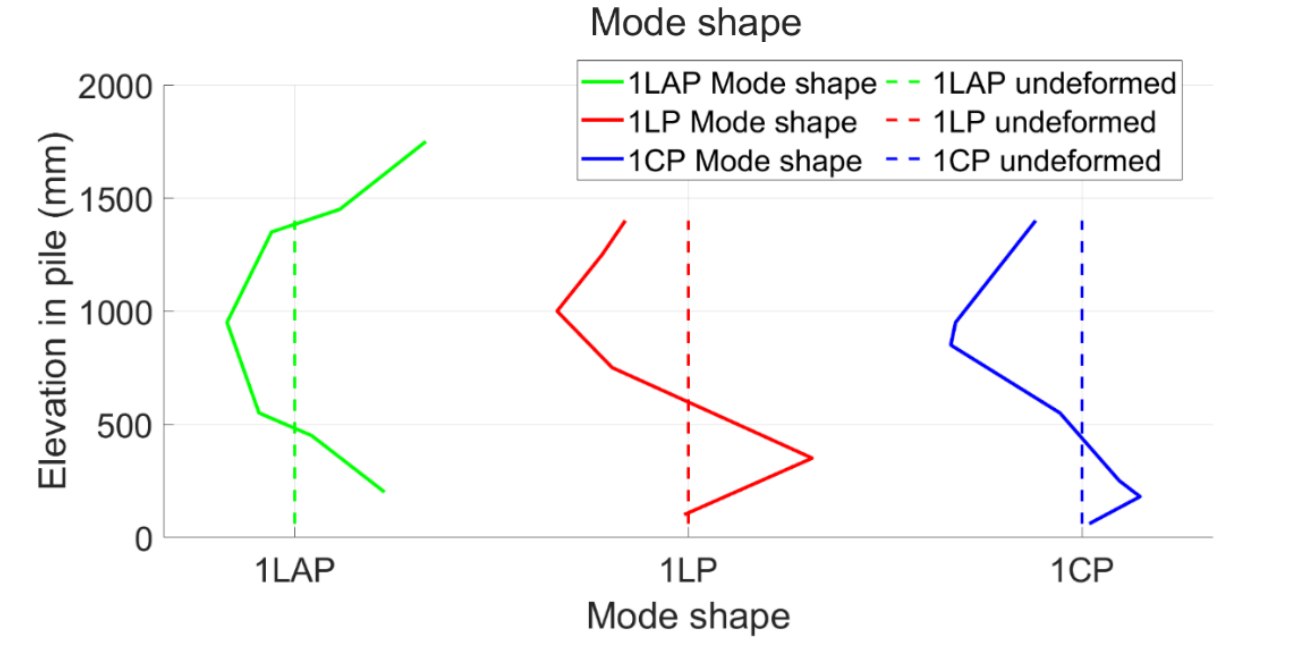

(b)

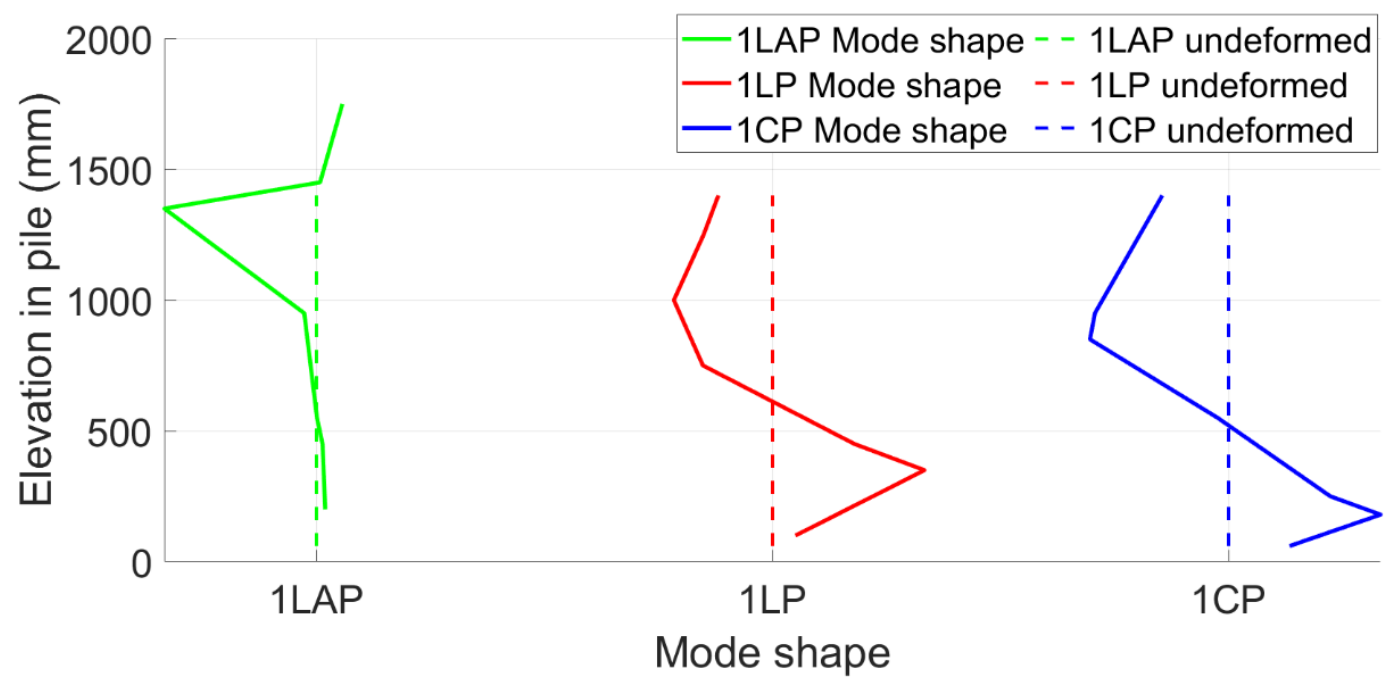




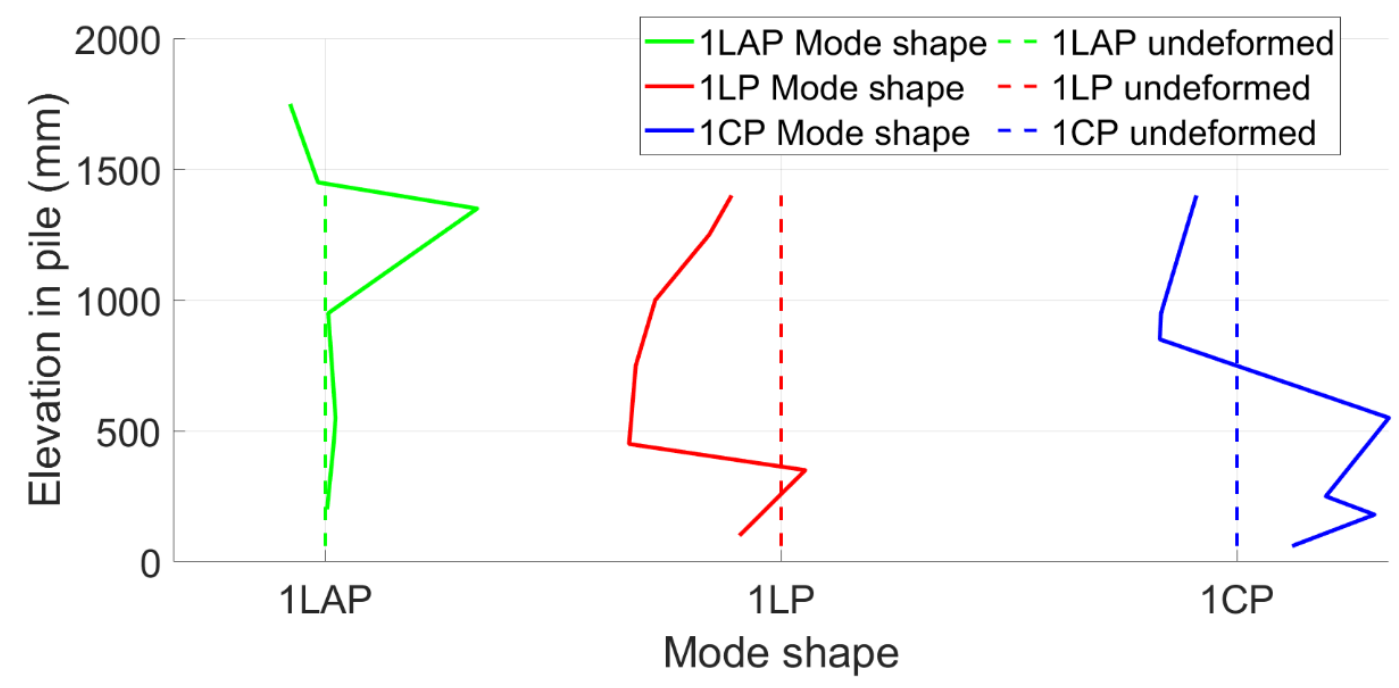

(d)

Mode shape

Fig. 17 Mode shapes of piles for different phases of the test: (a) Phase 1; (b) Phase 2; (c) Phase 3; (d) Phase 4

Table 3 Natural frequency during the free vibration tests with only dead loads

\begin{tabular}{|l|l|l|l|}
\hline & Natural frequency for various soil fill condition (Hz) (dry condition) \\
\hline Pile Name & Without any soil & With gravel & $\begin{array}{l}\text { With gravel and } \\
\text { sand }\end{array}$ \\
\hline $\mathbf{1 L A P}$ & 4.97 & 10.9 & 12.9 \\
\hline $\mathbf{1 L P}$ & 0.90 & 1.17 & 2.7 \\
\hline $\mathbf{1 C P}$ & 0.808 & 1.34 & 2.4 \\
\hline
\end{tabular}

Table 4 Natural frequency during the free vibration tests with decks placed on top of piles

\begin{tabular}{|l|l|l|l|}
\hline & \multicolumn{3}{|l|}{ Natural frequency for various soil fill condition (Hz) (dry condition) } \\
\hline Pile Name & Without any soil & With gravel & $\begin{array}{l}\text { With gravel and } \\
\text { sand }\end{array}$ \\
\hline $\mathbf{1 L A P}$ & 1.62 & 3.30 & 8.05 \\
\hline $\mathbf{1 L P}$ & 1.6 & 3.27 & 7.78 \\
\hline $\mathbf{1 C P}$ & 1.54 & 3.14 & 7.74 \\
\hline
\end{tabular}

\subsection{Lateral displacement of piles:}

The lateral displacements of the piled supports were measured with the help of wire potentiometers. One of the ends of measuring wire of potentiometers were tied at the pile caps as shown in Fig. 5 and the other end was installed in a fixed frame outside the shaking table. The potentiometers DT1, DT2, DT3 were installed at the pile caps of $1 L A P, 1 L P$ and $1 C P$ respectively. The time history of lateral displacement of these piled supports are given in Fig. 18. It is quite evident that the readings of the potentiometers have two components; residual displacement (monotonic component) and cyclic displacement. The residual component of the lateral displacement has been delineated in Fig. 18(a), by filtering out the dynamic component of it. The cyclic component of the lateral displacement of different piles are given in Fig. 18(b). Moreover, the relative displacement of the central pile 1CP with respect to the intermediate pile $1 L P$ is given in Fig. $18(\mathrm{~d})$. This can be obtained by subtracting the time history of the lateral displacement of $1 L P$ from that of the central pile $1 C P$. These are discussed in detail in the next sections. 


\section{Cyclic displacement of piles:}

As it has been hypothesized that as the central piles become more flexible in case of liquefaction they tend to deflect more as compared to other bridge supports, it was decided to compare the cyclic component of the displacement of all the piles of the model bridge. The cyclic displacement for the pile $1 C P$ has been determined by 'highpass' filtering the potentiometer data with a cut-off frequency of $0.2 \mathrm{~Hz}$ and is given in Fig. 18(b). It can be observed in the figure that as soon as the liquefaction starts in shallow layers of soil in Phase 2 of input motion, the cyclic displacement starts increasing. It can be observed that as the full liquefaction happened for 160-186 seconds duration, the cyclic displacement of 1LP and 1CP became higher as compared to that of the abutment support 1LAP. But as the dilation of the overlying sand happened just after the full liquefaction at around 186 seconds and the pore water pressure dropped down, the central pile and the abutment support had almost same cyclic displacement (seen by overlapping yellow and blue lines in rest of Phase 3 and Phase 4 in Fig. 18(b)). The envelope of the peaks of cyclic lateral displacement of pile 1CP and 1LAP is given in Fig. 18(c) for the ease of comparison. Although the difference in the cyclic displacement of both the piles was in the order of $2-3 \mathrm{~mm}$, it can be appreciated that such a difference in displacement was clearly exhibited for the scaled down model test, where the difference in unsupported length across two different bridge supports is quite less as compared to that of a real field scenario. As the confining stress available for soil is quite less in a shake table test as compared to that of the real field, the lateral displacement measured in these tests undermines the actual displacement of a pile for its response to an equivalent earthquake in the field. It is of interest to note here that the cyclic component of the lateral displacement is mainly contributed due to the vibration of unsupported length of the pile and the superstructure inertial load. Hence, although the inertial load reduces to a greater extent after liquefaction, it must be the vibration of enhanced unsupported length of the pile, which may have contributed to the higher cyclic lateral displacement of the central pile. Moreover, the order of cyclic displacement of the piles reduced in the fourth phase of input motion, as the pile started behaving stiffer, as evident from the increase in its natural frequency.

Further, the time history of relative lateral displacement demand on the central pile as compared to that of the intermediate pile $1 L P$ is shown in Fig.18(d). It can be obtained by subtracting the lateral displacement of pile $1 L P$ from that of the central pile $1 C P$ at different instances of time. It can be observed that this relative displacement started increasing in the second phase of loading as the central pile started having higher displacement due to the increased flexibility, rendered due to the liquefaction of shallower layers of soil. On the other hand, there was not much lateral spreading of soil in the second phase of loading as can be seen from the time history of displacement from readings of DT1 and DT2. This relative lateral displacement kept on increasing and had its maximum value of $2 \mathrm{~mm}$ at around $180-200$ seconds. It is to be noted here that the central bridge support having the pile $1 C P$ had its lowest natural frequency also around this time (in time duration of 160-186 seconds). It clearly indicates that the displacement of the central pile gets significantly affected due to increased flexibility of the pile due to the loss of surrounding soil stiffness, and it also results in differential displacement demand between the adjacent piers. Thereafter, the relative displacement between these two piles did not increase much, as the pile $1 L P$ started having higher lateral displacement due to the lateral spreading of surrounding soil.

It can be observed that all the piles had differential lateral displacement due to the multitude of factors. For the piles of the abutments and its adjacent supports, the lateral displacement 
may get significantly induced by the lateral spreading of soil. But for the central piles, the increase in the flexibility of piles due to liquefaction in soil may induce higher displacement demand and it may happen at a time earlier than that of the lateral spreading of soil. This effect can sometimes induce much higher lateral displacement demand on the central piles as compared to the adjacent ones, depending upon the surrounding soil stiffness.
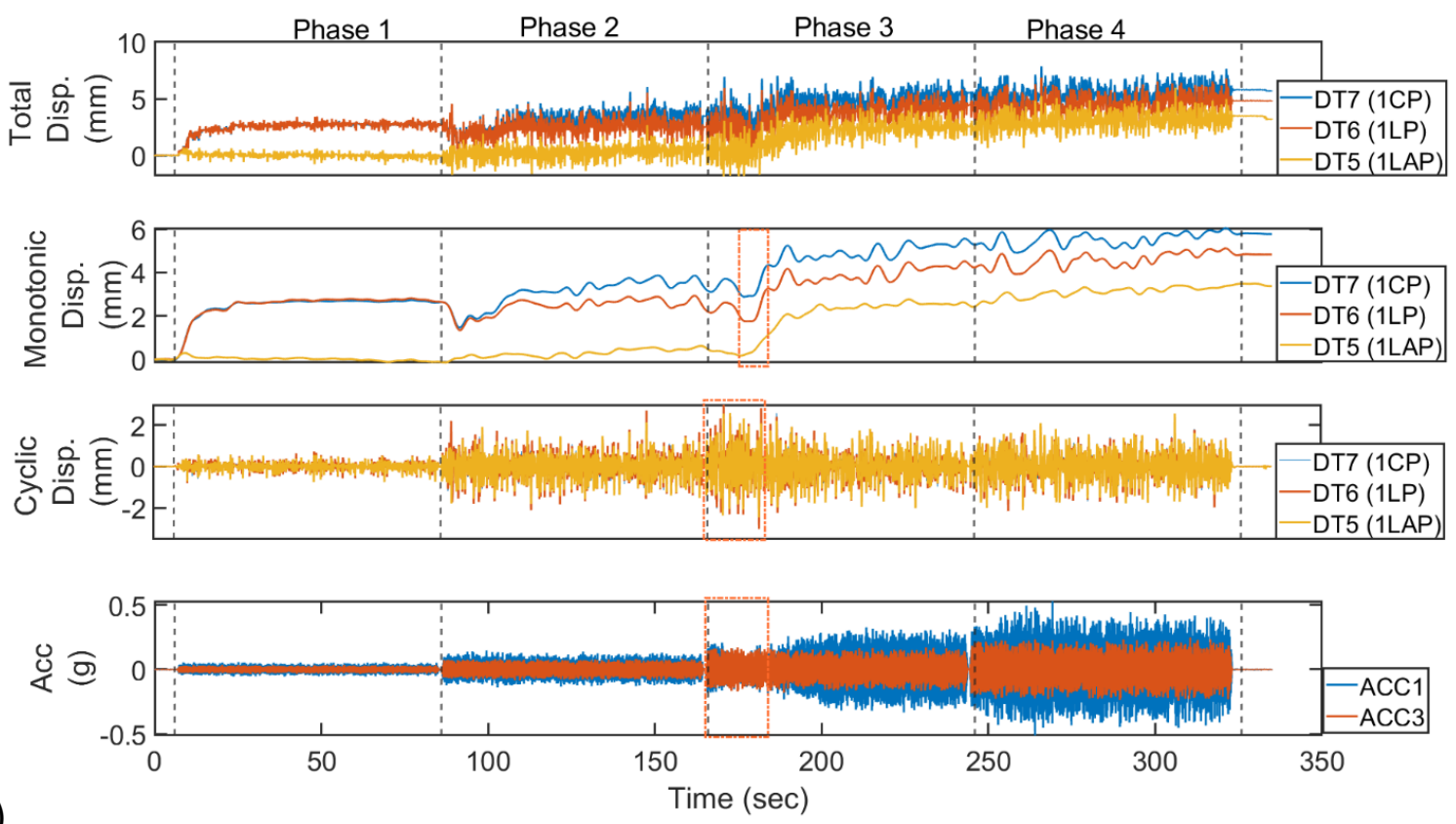

(a)

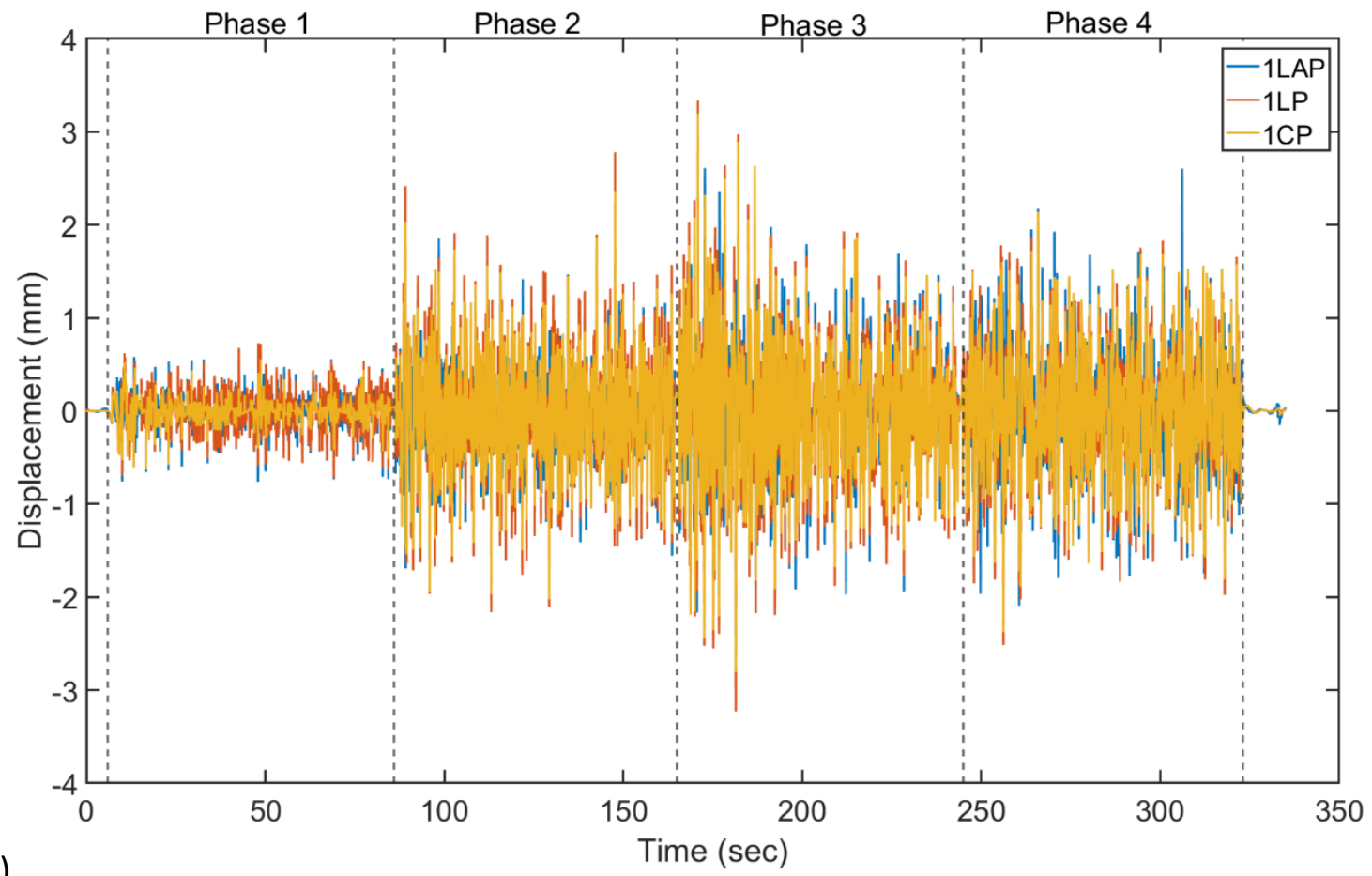


(c)
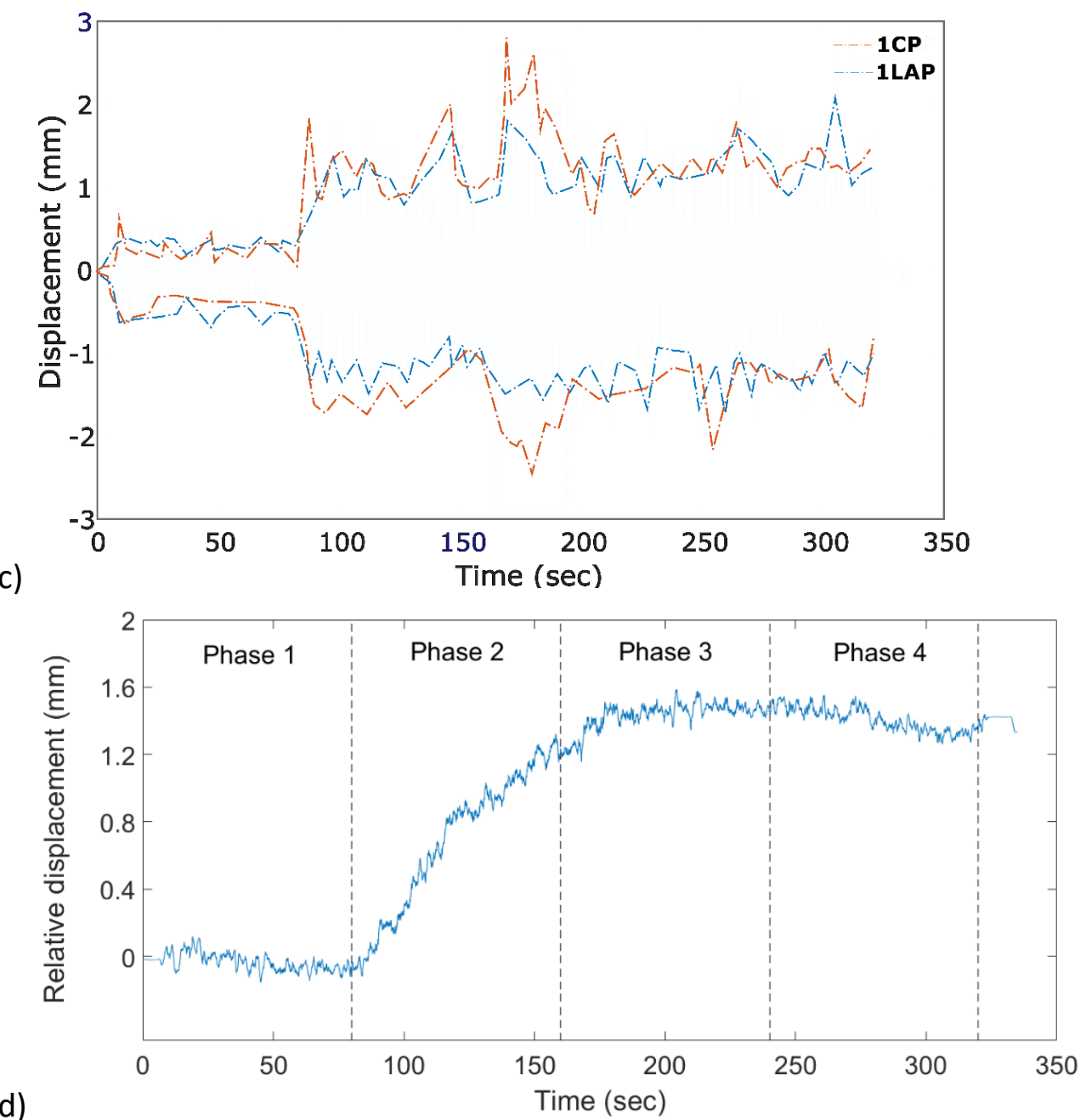

Fig. 18 Variation in lateral displacement of various bridge supports during the test: (a) Comparison of displacements of piled bridge supports; (b) Comparison of cyclic displacements of $1 L A P, 1 L P$ and $1 C P ;$ (c) Envelope of cyclic displacement of $1 C P$ and $1 L A P$ as taken from Fig. 18 (b) ; (d) Relative displacement of $1 C P$ with respect to $1 L P$

\subsection{Bending moment:}

Seven pairs of strain gauges were used in each of the piles of $1 C P$ and $1 L P$ and one of the piles of $1 L A P$ to measure their bending strains during the process of liquefaction as shown in Fig. 9 (d). The piles having strain gauges are indicated by the hatching marked piles in Fig. 19. These bending strains are further employed to calculate the bending moment in those piles. The strain gauge data were filtered with the help of Butterworth bandpass filter with cut off frequency at $1 \mathrm{~Hz}$ and $15 \mathrm{~Hz}$ to eliminate the unwanted drift and high frequency noise. Some of the strain gauges also malfunctioned during the tests. Hence, the data presented hereafter will be devoid of those faulty strain gauges. Moreover, as the bending moment data presented in this section are already filtered out for frequencies lesser than $1 \mathrm{~Hz}$, the monotonic component of bending moment of pile is not included in the estimation.

The bending moments of these piles at different instances of time are plotted in Fig. 20, 21 and 22. Further, curve fitting methods are employed for the smooth moment distribution of the piles with the help of polynomial function of appropriate degree, for each of the cases. Central Pile ( $1 C P)$ : 
The depth of various strain gauges from the pile cap has been denoted in the Fig. 20 (a) and the strain gauge locations are being numbered as $S 5, S 4, S 3, S 2$ and $S 1$ from the top to tip of the pile respectively. The bending moments at various sections of the central pile 1CP is given in Fig. 20 (b). For the strain gauge pair at $S 5$ and $S 4$, which are placed at a higher elevation as compared to other strain gauges, the bending moment is more in Phase 1 and Phase 2 as compared to the other strain gauges. Before the liquefaction, the soil has higher shear strength and hence, the acceleration imparted to the superstructure was higher. As a result, the bending moment at these two locations progressively increased with the increment in inertial load. But the inertial load could not distress the deeper soils. Hence, the bending moment is less for the strain gauges, which are placed deep inside the soil, e.g. S3, S2 etc. for the initial 2 phases of input motion. Further, it can be observed that the bending moment for sections $S 5$ and $S 4$ reaches its maximum value during the process of liquefaction as indicated by the broken red rectangle. In fact, the bending moment for the pile $1 C P$ attained its maximum value at the section 54 during this time.

From the estimated bending moment time histories at different sections, the time instance of maximum bending moment for the pile is identified, which happened at around 168 seconds for the section near 54 . It corroborates the fact that the maximum bending moment in the pile is achieved during the transient process (just before the full liquefaction is achieved). The bending moment at other sections of the pile at the same time instant has been plotted in Fig. 20(c). All the bending moment values are plotted in their absolute values for the sake of comparison. Further, a polynomial equation of 5 th order has been fitted for the distribution of bending moment in pile at various sections, at the time of maximum bending moment. It is quite interesting to note here for the pile $1 C P$ that the location of maximum bending moment is at a higher elevation in the pile (1m from the pile tip), rather than at the interface of liquefied and non-liquefied soil layer, which is evident from the fitting curve as well.

The previous research on the estimation of bending moment in pile in liquefied soil also posited that the maximum bending moment happens during the transient process, i.e., just before the $r_{u}$ reaches the value of unity $[7,35]$. But all these researches were aimed at effect of lateral spreading of soil on the piles, hence the maximum bending moment was located at the interface of liquefied-nonliquefied soil.

Once the full liquefaction has occurred, the acceleration of the pile head of $1 C P$ reduces due to higher damping of liquefied soil. It has been reported by the researcher [19] that the damping of soil can increase up to a value as high as $20 \%$ in case of liquefaction. Consequently, the higher bending moment for the strain gauge locations in shallow layers of soil, e.g. S4 reduces. But for the strain gauges placed deeper inside the soil, e.g. S3 and S2, the bending moment kept on increasing as the input acceleration was increased due to increase in the kinematic loading. It can therefore be observed that before the liquefaction, the inertial load due to superstructure has a higher impact on the bending moment, which is effective in the shallow depths of soil. But as soon as liquefaction happens in the soil, the bending moment of the pile gets affected by the kinematic load applied by the surrounding soil.

It is of interest to denote here that the pile $1 C P$ experienced maximum bending moment during the process of liquefaction at location S4. It can happen due to both the effects as mentioned below.

1) The inertial load on the pile head, which has not dropped to its lowest level as it happens at full liquefaction. 
2) Increased flexibility of pile which allows the pile to displace more due to loss of stiffness in the surrounding soil. This factor induces the higher bending moment in the pile at a higher elevation towards the pile cap, not necessarily at the interface of the liquefiable and nonliquefiable soil layer. As per the current practice adopted, the plastic hinge in the pile is usually considered near the pile cap, or at the interface of liquefied-nonliquefied soil layer, which may ignore the location of actual plastic hinge in the pile.

\section{Abutment pile (1LAP)}

The depth of various strain gauges of the instrumented pile of abutment 1LAP has been denoted in the Fig. 21 (a). The bending moments at various sections of the abutment pile is given in Fig. 21(b). It can be observed that the bending moment of the pile at strain gauge pair S3 and S5 in pre-liquefaction phase (Phase 1 and Phase 2) were higher due to the higher inertial load, owing to less damping of the non-liquefied soil. Moreover, as the piles were rigidly connected at the pile cap, higher bending moment was also induced in the sections closer to the pile cap. But the effect of this higher bending moment is less for the strain gauges S2 and S1, which are placed on the pile section, deep inside the soil layer. Once the liquefaction has occurred, the acceleration of the pile head reduces due to higher damping of liquefied soil. Consequently, the bending moment for the strain gauge $S 5$ and $S 3$ reduces. But for the strain gauges placed deeper inside the soil, e.g. $S 2$ the bending moment kept on increasing in the Phase 3 and Phase 4 of input motion due to kinematic loading of soil. It can therefore be deduced that for the abutment piles before the full liquefaction, the inertial load due to superstructure has a higher impact on the bending moment of the pile section in the shallower depth of soil. But later, higher bending moment is observed near to the interface of liquefied-nonliquefied soil layer, due to lateral spreading of soil after the full liquefaction. From the estimated bending moment time histories at different sections, the time instance of maximum bending moment is identified, which happened at around 288 seconds for the pile section near 52 . The bending moment at other sections of the pile at the same time instant has been plotted in Fig. 21(c). All the bending moment values are plotted in their absolute values for the sake of comparison. Further, a polynomial equation of 4 th order has been fitted for the distribution of bending moment in pile at the instant of maximum bending moment. It is quite interesting to note that the maximum bending moment in the pile is observed near the interface of liquefied-nonliquefied soil layer for instrumented pile of $1 L A P$. Intermediate Pile (1LP):

The bending moments at various sections of the intermediate pile $1 L P$ is given in Fig. 22 . It can be observed in Fig. 22(b) that the higher bending moment at strain gauge pair $S 4$ and S3 in pre-liquefaction phase (Phase 1 and Phase 2), can be attributed to the higher inertial load at the pile cap due to less damping of the non-liquefied soil. But the effect of this higher bending moment during the pre-liquefaction phase is less for the strain gauges $S 2$ and $S 1$, which are placed deep inside the soil. It can also be observed that the bending moment for sections $S 4$ and $S 3$ reaches its maximum value during the process of liquefaction as indicated by the broken red line. It can be attributed to the increased displacement of the pile $1 \mathrm{LP}$ due to the enhanced flexibility of the pile (as it happens at a higher elevation as compared to that of the interface of liquefied-nonliquefied soil layer).

From the estimated bending moment time histories at different sections, two critical bending moment profiles were identified for the intermediate pile $1 L P$, one during the process of liquefaction at around $t=169$ seconds and one at the time of lateral spreading $t \mathrm{t}=262$ seconds. The bending moment at all the sections of the pile at these two time instances has 
been plotted in Fig. 22(c). All the bending moment values are plotted in their absolute values for the sake of comparison. Further, a polynomial equation of 5 th order has been fitted for the distribution of bending moment in the pile at the instant of maximum bending moment for both the occasions. It is quite interesting to note here that there are two maximas of bending moment in the pile during the process of liquefaction (when the soil has not fully liquefied up to the maximum depth); i.e. one near to the interface of liquefied-nonliquefied soil layer and the other one more towards the pile cap. However, much later during the lateral spreading phase, the maxima of bending moment lies near to the interface of liquefiednonliquefied soil layer.

It can therefore be deduced that before the full liquefaction happens, the inertial load due to superstructure has a higher impact on the bending moment of the pile section in the shallower depth of soil. But as soon as the soil liquefaction process is initiated near the intermediate pile (which can also be susceptible to lateral spreading), the higher bending moment is induced in the upper section of the pile and near the interface of liquefiednonliquefied soil layer. This may happen as the intermediate pile $1 L P$ is affected by the increased displacement demand owing to enhanced flexibility of pile for higher bending moment near the upper section of pile. Further, it also may get influenced by the minor lateral spreading of soil at the interface of both the soil layers. But after the full liquefaction happens, the higher bending moment is observed only near the interface of these two layers due to lateral spreading of soil.

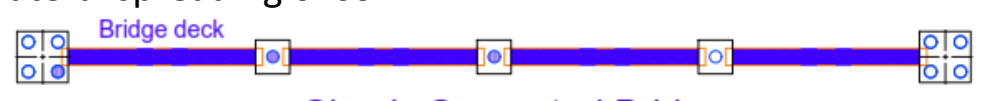

Simply Supported Bridge

Legend:

- Piles having strain gauges

Fig. 19 Hatching marked piles have strain gauges attached at different elevations
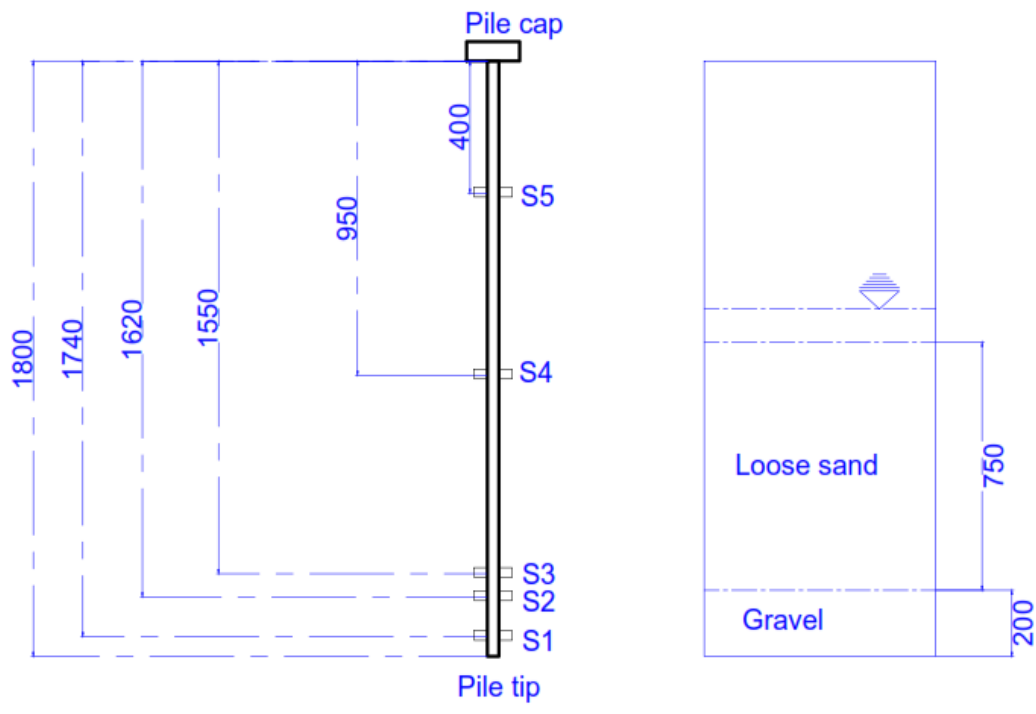

(a)

$\square$ Strain Gauge 
(b)
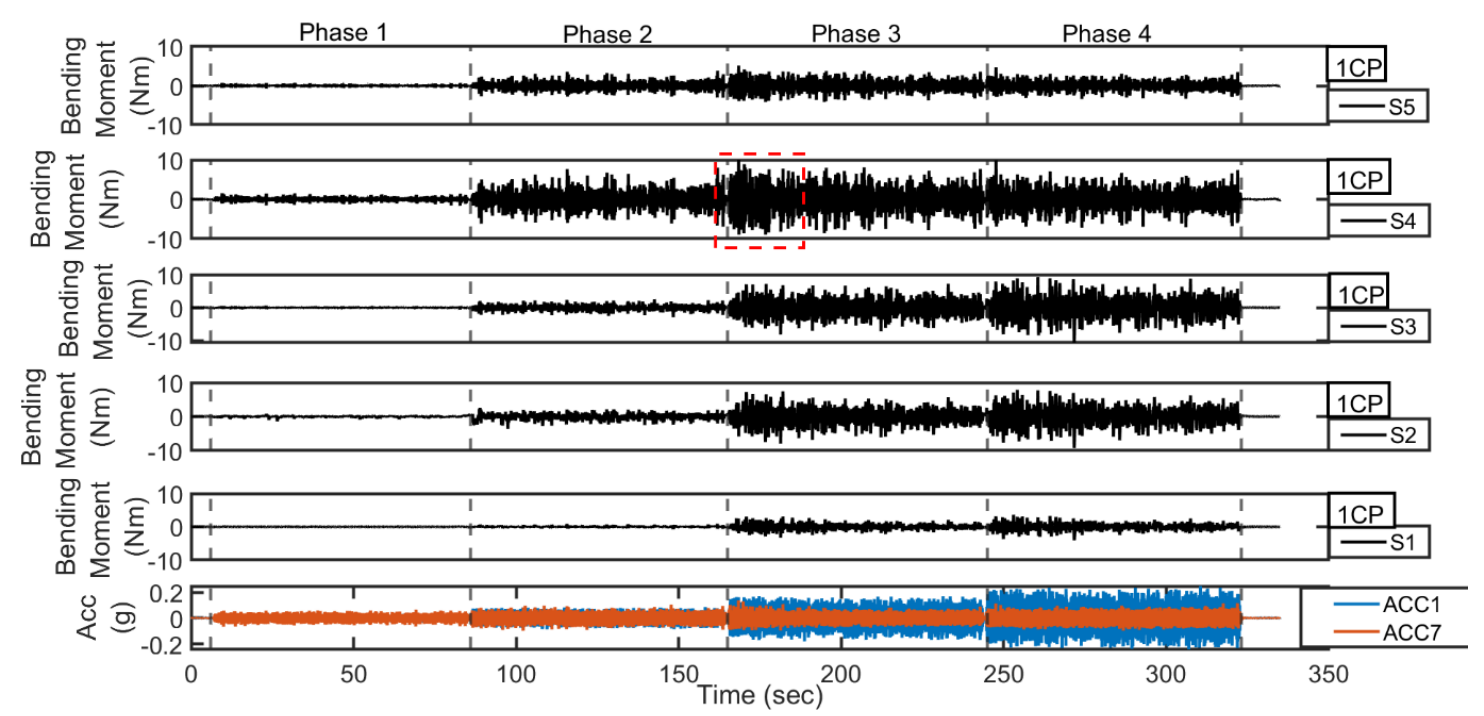

(c)

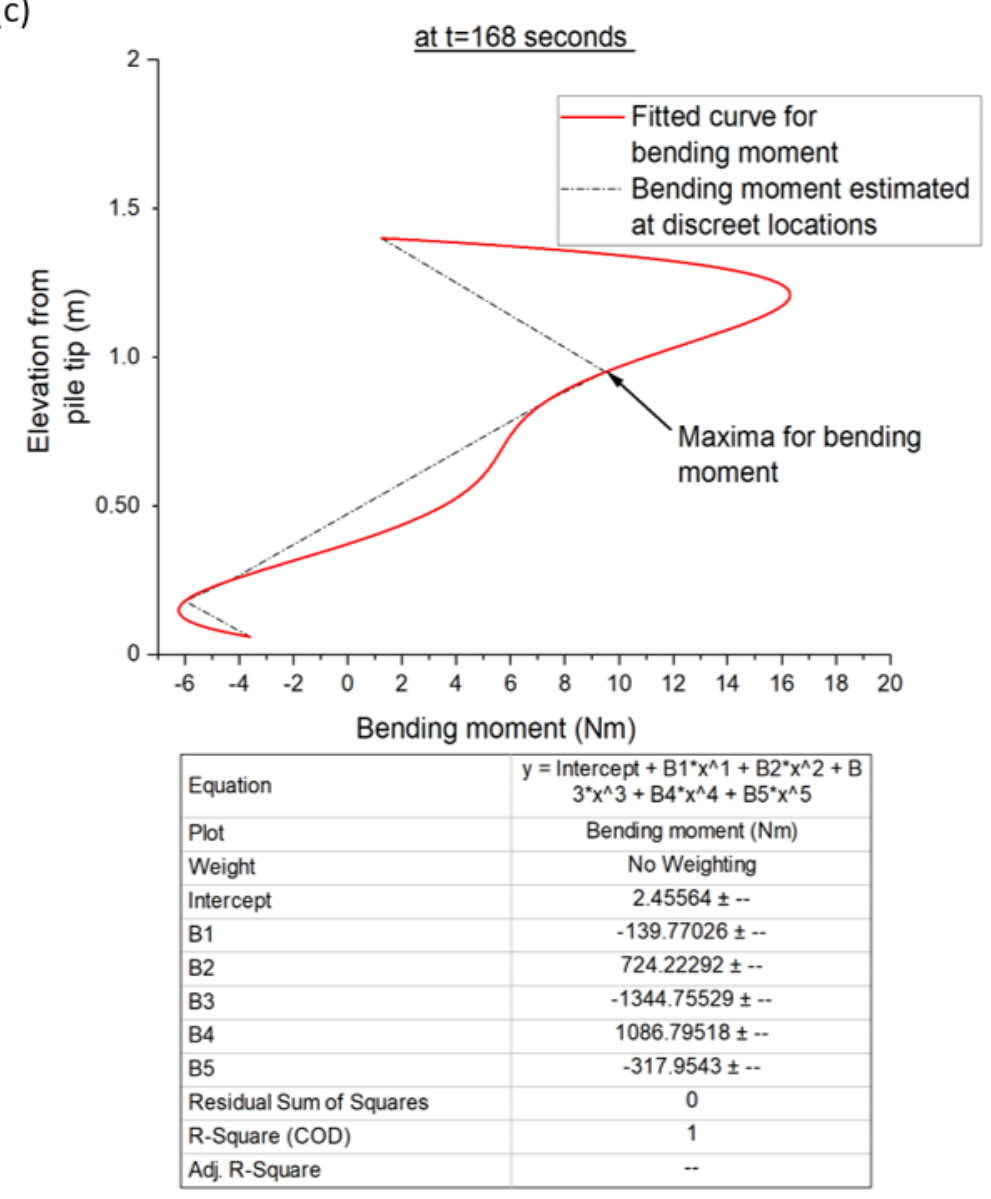

Fig. 20 (a) Location of strain gauges in pile 1CP; (b) Time history of bending moment at various sections of the pile 1CP with the input motion; (c) Fitting curve for bending moment distribution at different sections of pile 1CP; 
(a)
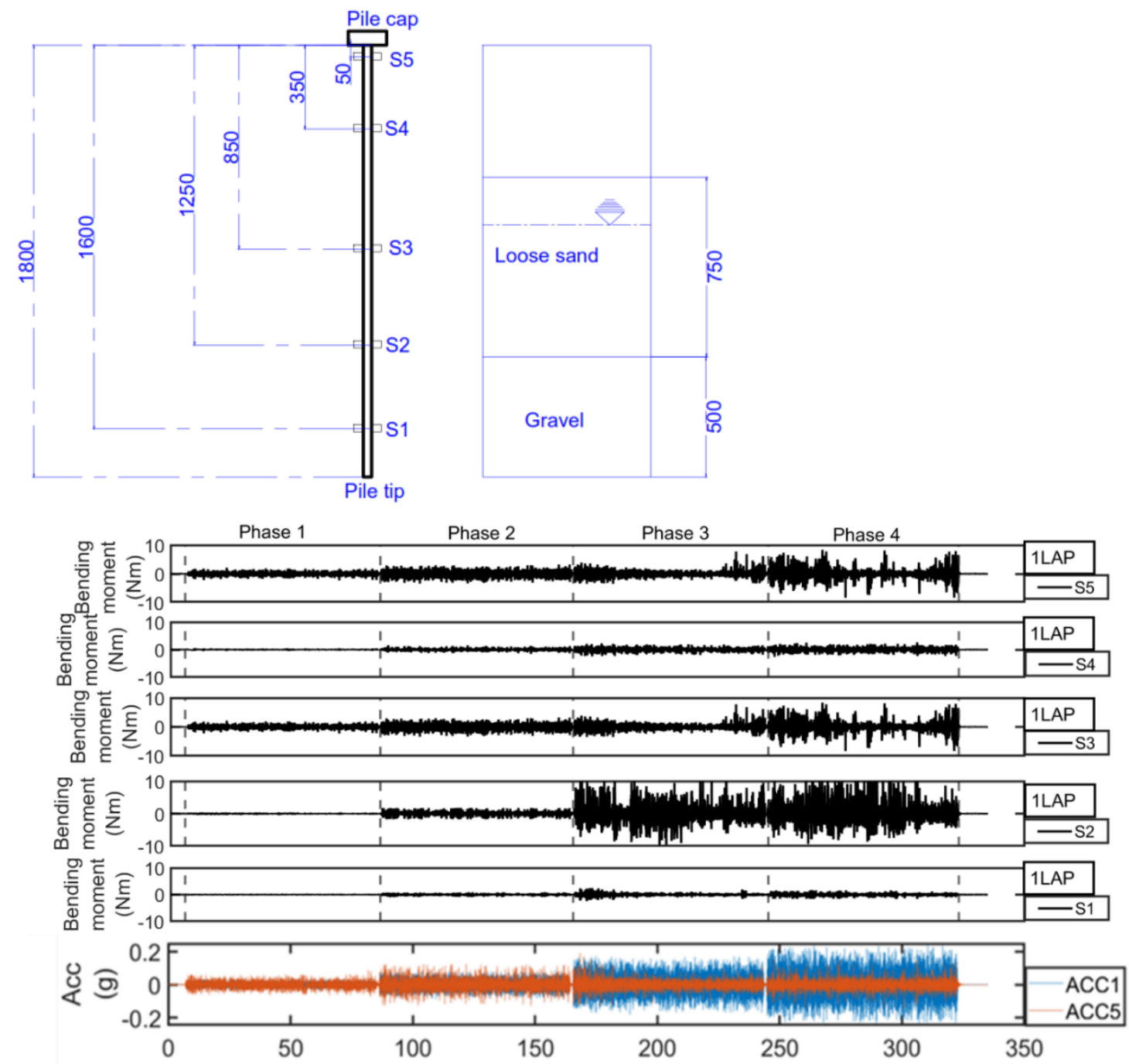

(b)

Time (sec) 
(c)
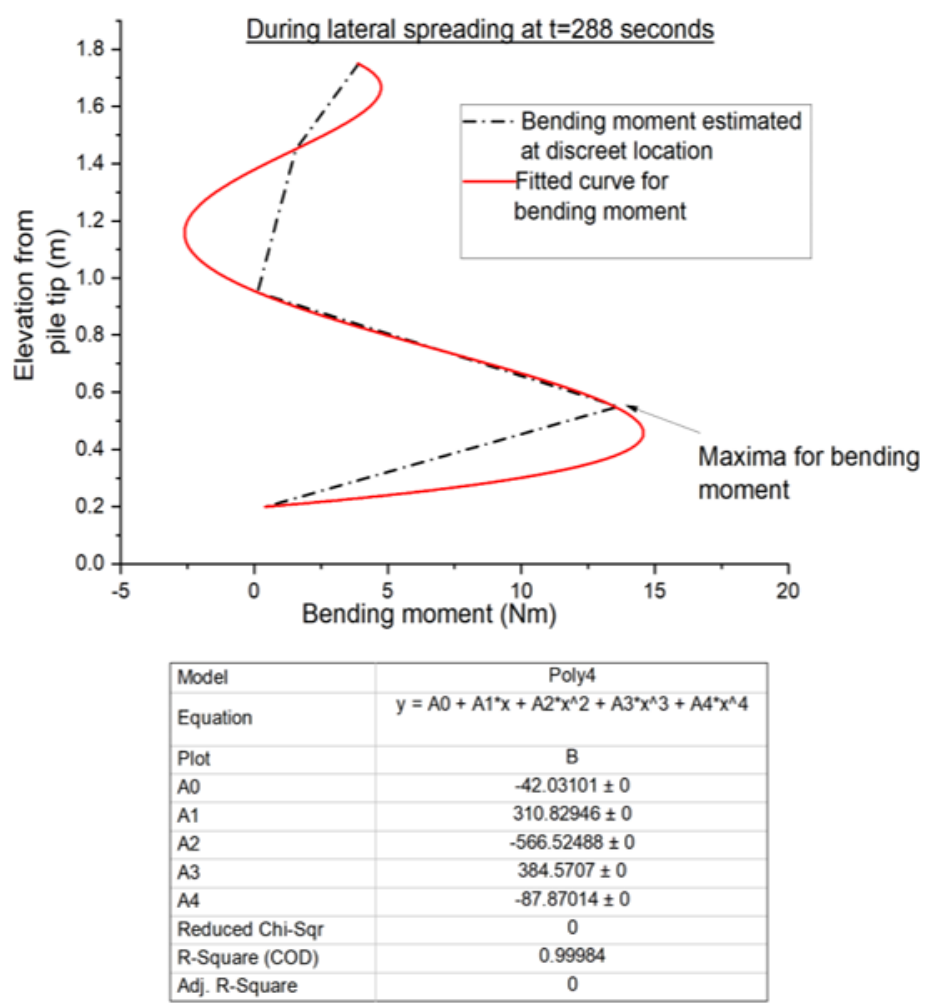

Fig. 21 (a) Location of strain gauges in pile 1LAP; (b) Time history of bending moment at various sections of the pile 1LAP with the input motion; (c) Fitting curve for bending moment distribution at different sections of pile;
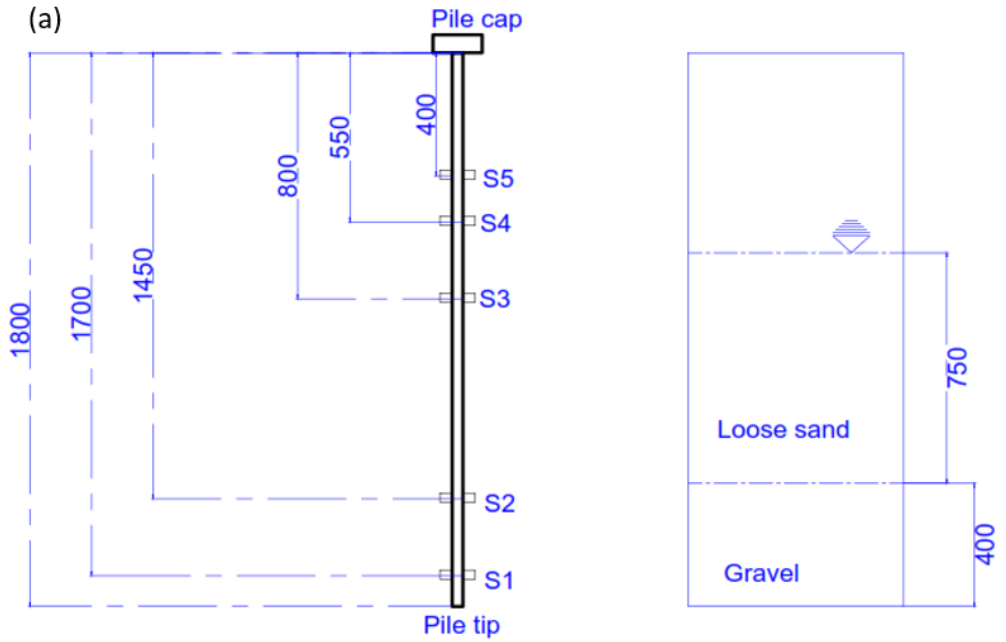

$\square$ Strain Gauge

(b) 


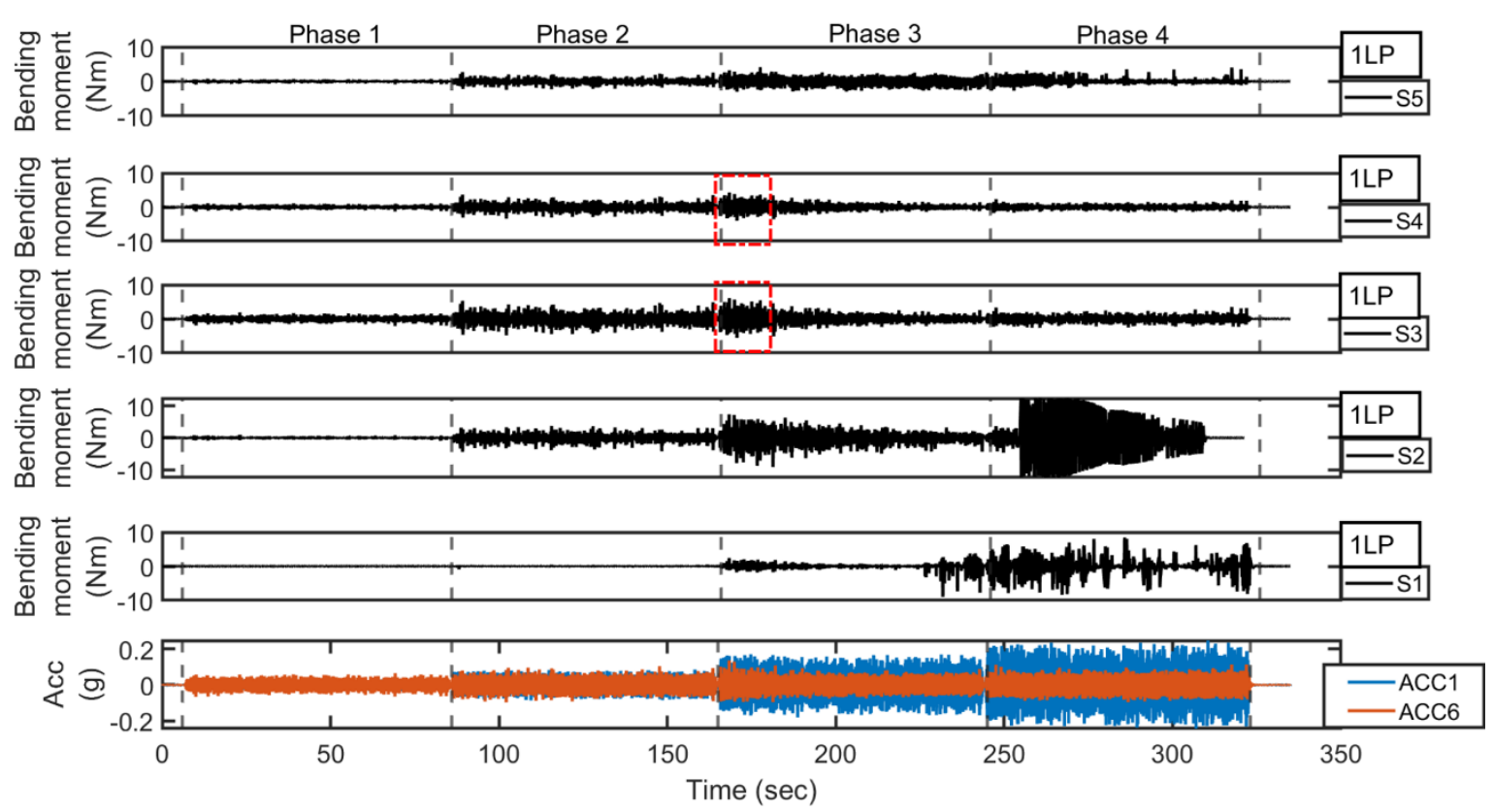

(c)
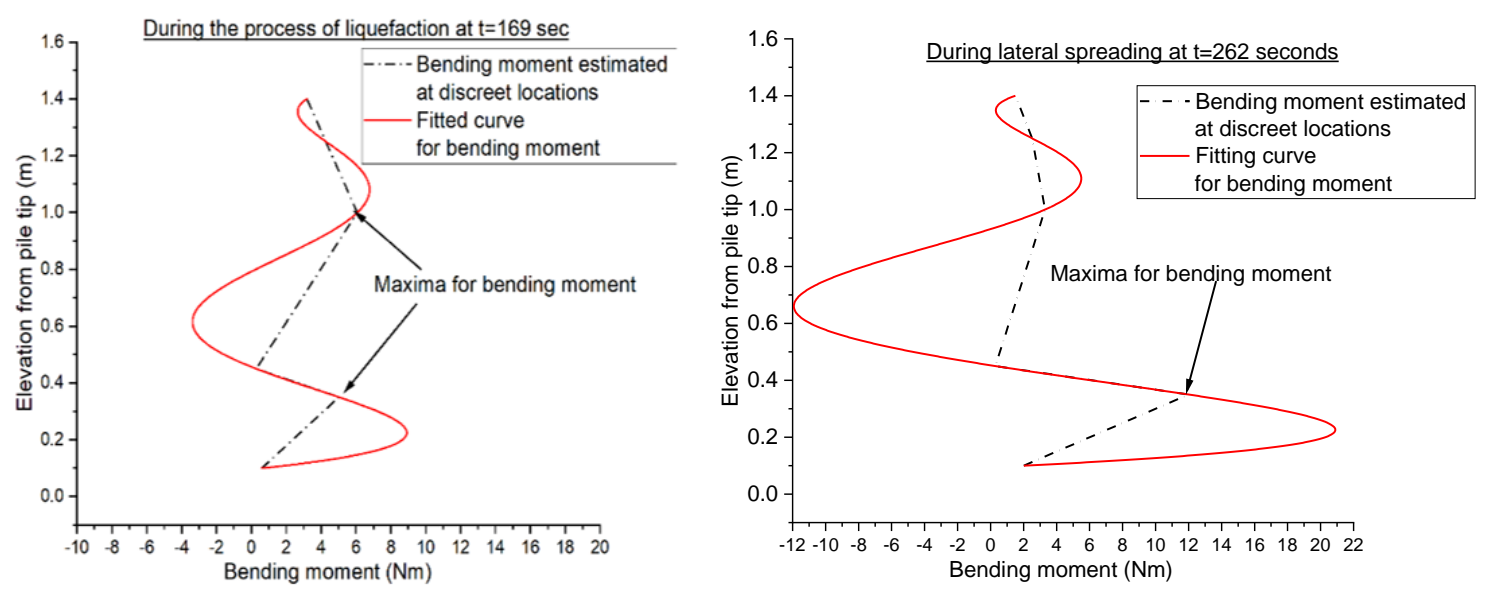

Fig. 22 (a) Location of strain gauges in pile 1LP; (b) Time history of bending moment at various sections of the pile 1LP with the input motion; (c) Fitting curve for bending moment distribution at different sections of pile;

\section{Summary and conclusions:}

An experimental investigation on a model simply supported bridge is carried out in the shaking table to verify the mechanisms behind the midspan collapse of pile supported bridges in liquefied soil. The design of model simply supported bridge was inspired from the prototype Shengli bridge of China. The model bridge was constructed in a stratified soil with the loose sand layer overlying the non-liquefying dense gravel layer. The white noise was used as input motion for the tests to liquefy the soil.

The following salient points have been concluded from the current study:

(1) The natural frequency of the pile supported bridge piers reduces as the liquefaction sets in. As the depth of liquefaction increases for the surrounding soil gradually, the natural frequency of the pier reduces progressively. The bridge supports attain their lowest natural frequency near around the time of full liquefaction.

(2) Due to the inherent differential stiffness of the bridge piers due to its river profile, the piers may have differential reduced natural frequency at the time of full liquefaction. This 
imposes differential lateral displacement demand and differential bending moment demand on consecutive piers. Hence, all the piled bridge supports must be assessed for their critical condition during liquefaction individually.

(3) The piles founded in the sloped portion of the river cross section can have higher bending moment demand due to the lateral spreading of soil. In such a case, the maximum bending moment in the pile may occur near the interface of liquefied-nonliquefied soil layer. But piles of central piers and its adjacent piers can have higher bending moment demand due to the increased flexibility on account of liquefaction in soil. In such a scenario, the maximum bending moment in the pile will occur at a much higher elevation, as compared to that of the interface of soils of varied stiffness.

(4) As a result, the location of plastic hinge may change for different piled supports of the bridge, depending on its location with respect to the river cross section, shape of the river bed profile near it . As per the current practice adopted, the plastic hinge in the pile is usually considered near the pile cap, or at the interface of liquefied-nonliquefied soil layer, which may ignore the location of potential plastic hinge in the pile.

These research findings have not been addressed specifically in various regional codes. Hence, there can be a risk of such bridge failures in many countries. Further studies are required to evaluate and validate the reduction in natural frequency of the bridge supports during liquefaction quantitively. Moreover, additional study is also required to address this failure mechanism quantitively and to design the retrofitting strategy for such existing bridges, which are vulnerable to failure due to their reduced natural frequency during liquefaction.

\section{Acknowledgement:}

We acknowledge the support extended by the team of Prof Tao Wang, Mr Du Chunbo Institute of Engineering Mechanics, China Earthquake Administration (CEA) for carrying out the scaled down model tests on bridges in liquefiable soil in their laboratory facilities at Hebei, China. Further, the financial grant provided by the Great Britain China Centre (GBCC) is also gratefully acknowledged.

\section{Notations:}

ACC: Accelerometers

CP: Central Pile

DT: Displacement transducers (Wire potentiometers)

EPWR: Excess Pore water pressure ratio

LAP: Left Abutment Pile

LP: Left Pile

PPT: Pore pressure transducers

RAP: Right Abutment Pile

RP: Right Pile

STFT: Short-time Fourier transform

\section{Reference:}

[1] Orense R, Ishihara K, Yasuda S, Morimoto I, Takagi M. Soil spring constants during lateral flow of liquefied ground. In: New Zealand Society for Earthquake Engineering, editor. 12th World Conf. Earthq. Eng., Upper Hutt, N.Z. : New Zealand Society for Earthquake Engineering; 2000, p. Paper no 2099. 
[2] Kato K, Gonzalez D, Ledezma C, Ashford S. Analysis of pile foundations affected by liquefaction and lateral spreading with pinning effect during the 2010 Maule Chile earthquake. NCEE 2014 - 10th US Natl Conf Earthq Eng Front Earthq Eng 2014. https://doi.org/10.4231/D3KS6J54D.

[3] Franke KW, Rollins KM. Lateral Spread Displacement and Bridge Foundation Case Histories from the 1991 Magnitude 7.6 Earthquake near Limón, Costa Rica. J Geotech Geoenvironmental Eng 2017;143:05017002. https://doi.org/10.1061/(ASCE)GT.19435606.0001653.

[4] Caltrans. Guidelines on Foundation Loading and Deformation Due to Liquefaction Induced Lateral Spreading 2012:1-44.

[5] Chang BJ, Hutchinson TC. Experimental investigation of plastic demands in piles embedded in multi-layered liquefiable soils. Soil Dyn Earthq Eng 2013;49:146-56. https://doi.org/10.1016/j.soildyn.2013.01.012.

[6] Ebeido A, Elgamal A, Tokimatsu K, Abe A. Pile and Pile-Group Response to LiquefactionInduced Lateral Spreading in Four Large-Scale Shake-Table Experiments. J Geotech Geoenvironmental Eng 2019;145:04019080. https://doi.org/10.1061/(ASCE)GT.19435606.0002142.

[7] Motamed R, Towhata I. Shaking Table Model Tests on Pile Groups behind Quay Walls Subjected to Lateral Spreading. J Geotech Geoenvironmental Eng 2010;136:477-489. https://doi.org/10.1061/(ASCE)GT.1943-5606.0000115.

[8] Ishihara K, Yoshimine M. Evaluation of settlements in sand deposits following liquefaction during earthquakes. Soils and Foundations 1992;32:173-88.

[9] Knappett JA, Madabhushi SP. Liquefaction-Induced Settlement of Pile Groups in Liquefiable and Laterally Spreading Soils. J Geotech Geoenvironmental Eng 2008;134:1609-1618. https://doi.org/10.1061/(asce)1090-0241(2008)134:11(1609).

[10] API. Recommended Practice for Planning , Designing and Constructing Fixed Offshore Platforms - Working Stress Design. vol. 24-WSD. 2007.

https://doi.org/10.1007/s13398-014-0173-7.2.

[11] Bhattacharya S, Tokimatsu K. Essential criteria for design of piled foundations in seismically liquefiable areas. 39th Jpn. Natl. Conf. Geotech. Eng., Niigata, Japan: 2004, p. 1805-6.

[12] Haldar S, Sivakumar Babu GL, Bhattacharya S. Buckling and bending response of slender piles in liquefiable soils during earthquakes. Geomech Geoengin 2008;3:12943. https://doi.org/10.1080/17486020802087101.

[13] Shanker K, Basudhar PK, Patra NR. Buckling of piles under liquefied soil conditions. Geotech Geol Eng 2007;25:303-313. https://doi.org/10.1007/s10706-006-9111-6.

[14] Zhang X, Tang L, Li X, Ling X, Chan A. Effect of the combined action of lateral load and axial load on the pile instability in liquefiable soils. Eng Struct 2020;205:110074. https://doi.org/10.1016/j.engstruct.2019.110074.

[15] Wang X, Ye A, Shang Y, Zhou L. Shake-table investigation of scoured RC pile-groupsupported bridges in liquefiable and nonliquefiable soils. Earthq Eng Struct Dyn 2019;48:1217-1237. https://doi.org/10.1002/eqe.3186.

[16] Mohanty P, Dutta SC, Bhattacharya S. Proposed mechanism for mid-span failure of pile supported river bridges during seismic liquefaction. Soil Dyn Earthq Eng 2017;102:415. https://doi.org/10.1016/j.soildyn.2017.08.013. 
[17] Mohanty P, Bhattacharya S. Case studies of liquefaction induced damages to two pile supported river bridges in China. J Perform Constr Facil ASCE 2019;33. https://doi.org/10.1061/(ASCE)CF.1943-5509.0001306.

[18] Dammala PK, Bhattacharya S, Krishna AM, Kumar SS, Dasgupta K. Scenario based seismic re-qualification of caisson supported major bridges - A case study of Saraighat Bridge. Soil Dyn Earthq Eng 2017;100:270-5.

https://doi.org/10.1016/j.soildyn.2017.06.005.

[19] Lombardi D, Bhattacharya S. Modal analysis of pile-supported structures during seismic liquefaction. Earthq Eng Struct Dyn 2014;43:119-38. https://doi.org/10.1002/eqe.2336.

[20] Su L, Wan H, Li Y, Ling X. Soil-Pile-Quay Wall System with Liquefaction-Induced Lateral Spreading : Experimental Investigation, Numerical Simulation , and Global Sensitivity Analysis. J Geotech Geoenvironmental Eng ASCE 2018;144:1-17. https://doi.org/10.1061/(ASCE)GT.1943-5606.0001977.

[21] Saiidi MS, Vosooghi A, Nelson RB. Shake-Table Studies of a Four-Span Reinforced Concrete Bridge. J Struct Eng 2013;139:1352-61. https://doi.org/10.1061/(ASCE)ST.1943-541X.0000790.

[22] Yang C-Y, Cheung MMS. Shake Table Test of Cable-Stayed Bridge Subjected to NonUniform Excitation. Procedia Eng 2011;14:931-8. https://doi.org/10.1016/j.proeng.2011.07.117.

[23] Gade VK, Chauhan VB, Dasaka SM. Assessment of pluviation method of sand bed preparation by miniature cone penetration. Indian Geotech. J., Pune: Indian Geotechnical Society; 2015.

[24] Tsuchida H. Prediction and countermeasure against the liquefaction in sand deposits. Seminar in the Port and Harbor Research Institute, 3.1- 3.33. Semin. Port Harb. Res. Inst., 1970, p. 3.1-3.33.

[25] Tang L, Xu P, Ling X, Gao X. Shaking Table Test and Numerical Simulation For Seismic Soil-Pile-Bridge Structure Interaction In Liquefiable Ground. 14th World Conf. Earthq. Eng. 14WCEE, Beijing, China: 2008.

[26] Huixian L, Housner GW, Lili X, Duxin H. The Great Tangshan Earthquake of 1976. Tech Rep Caltech EERL2002001 2002;1.

[27] lai S. Similitude for shaking table tests on soil-structure-fluid model in 1g gravitational field. Soils Found 1 1989:2091.

[28] Wu X, Sun L, Hu S, Fan L. Development of laminar shear box used in shaking table test. Journal of Tongji University n.d.;30:781-5.

[29] Zeghal M, Elgamal A. Analysis of Site Liquefaction Using Earthquake Records. J Geotech Geoenvironmental Eng 1994;120:996-1017. https://doi.org/10.1061/(ASCE)07339410(1994)120:6(996).

[30] Tasiopoulou P, Gerolymos N, Tazoh T, Gazetas G. Pile-Group Response to Large Soil Displacements and Liquefaction: Centrifuge Experiments versus a Physically Simplified Analysis. J Geotech Geoenvironmental Eng 2013;139:223-33. https://doi.org/10.1061/(ASCE)GT.1943-5606.0000759.

[31] Haeri SM, Kavand A, Rahmani I, Torabi H. Response of a group of piles to liquefactioninduced lateral spreading by large scale shake table testing. Soil Dyn Earthq Eng 2012;38:25-45. https://doi.org/10.1016/j.soildyn.2012.02.002.

[32] Gabor D. Theory of Communication. J Inst Electr Eng 1946:429-57. 
[33] Calvi GM. Performance based approaches for seismic assessment of existing bridges. Proc. 11th Eur. Conf. Earthq. Eng., Paris: CRC Press; 1998.

[34] Priestley MJN, Seible F, Calvi GM. Seismic design and retrofit of bridges. 1996.

[35] He L, Elgamal A, Abdoun T, Abe A, Dobry R, Hamada M, et al. Liquefaction-induced lateral load on pile in a medium dr sand layer. J Earthq Eng 2009;13:916-938. https://doi.org/10.1080/13632460903038607. 